\title{
Triaxial Test and Mechanical Analysis of Rock-Soil Aggregate Sampled from Natural Sliding Mass
}

\author{
Shuling Huang, ${ }^{1}$ Xiuli Ding, ${ }^{1}$ Yuting Zhang, ${ }^{1}$ and Wei Cheng ${ }^{2}$ \\ ${ }^{1}$ Key Laboratory of Geotechnical Mechanics and Engineering of Ministry of Water Resources, \\ Changjiang River Scientific Research Institute, Wuhan, Hubei 430010, China \\ ${ }^{2}$ Sichuan Forestry Inventory and Planning Institute, Chengdu 610081, China
}

Correspondence should be addressed to Shuling Huang; huangsl_2014@163.com

Received 25 August 2014; Accepted 21 November 2014

Academic Editor: Guocheng Lv

Copyright (c) 2015 Shuling Huang et al. This is an open access article distributed under the Creative Commons Attribution License, which permits unrestricted use, distribution, and reproduction in any medium, provided the original work is properly cited.

\begin{abstract}
Rock-soil aggregate, as a specific geomaterial, exhibits complicated mechanical behavior. The rock-soil aggregate sampled from the deep layer of sliding mass at Jinpingzi area of Wudongde hydropower plant on Yangtze River is investigated to understand its mechanical behavior. Large-scale laboratory triaxial tests are conducted considering different gradations, stone contents and confining pressures. The results show that variation of stone content and gradation considerably affects the mechanical characteristics of rock-soil aggregate. Further, the influences of stone content, and gradation variation on stress-strain curve, MohrCoulomb criterion based shear strength parameters, Duncan-Chang model based deformation parameters, and internal friction angle are analyzed. A modified Rowe's stress-dilatancy equation describing the mechanical response of rock-soil aggregate is then suggested.
\end{abstract}

\section{Introduction}

The rock-soil aggregate is emerging as a new concept as the accumulation layered sliding mass receives increasing attention. Geomaterials, therefore, are further categorized into three existence forms, which are soil, rock, and rocksoil aggregate [1]. Rock-soil aggregates are widely distributed on the planet and already spotted in many engineering construction cases. Due to this practical need, the mechanical properties of rock-soil aggregate have been extensively addressed by many scholars. Particularly during the past decades, rock-soil aggregate gains its popularity as a hot issue in geotechnical scope.

Rock-soil aggregate in accumulation layered sliding mass is a natural geomaterial. It is composed of blocks, gravels, and fine grained soil of various dimensions. Due to this unique composition, it is characterized by high nonuniformity and discontinuity $[2,3]$. Its mechanical characteristics and deformation failure mechanism are therefore different from conventional geomaterials, such as soil and rock blocks [4-6]. The fabric features of rock-soil aggregate, including its granular composition, particle properties, and patterns of spatial distribution, have significant influences on its mechanical characteristics $[7,8]$.

For laboratory tests, researches are usually conducted based on a series of tests, including large-scale in situ shear test, laboratory shear test, laboratory uniaxial compressive test, and seepage test [9-12]. Strength and seepage parameters can be then obtained and adopted by engineering constructions. As for in situ test, the natural features of stone content, stone spatial distribution, and its gradation are maintained. However, rock-soil aggregates are randomly distributed. Due to this fact, as well as the restrictions caused by representativeness, operability, and financial cost, in situ tests cannot be conducted in large amounts. Moreover, for landslide occurring at deep layer with a sliding mass thickness greater than $25 \mathrm{~m}$, the stress state and stress path of rock-soil aggregate have significant impact on the evolution process of landslide. It is therefore not practical for in situ tests to provide different stress state and stress path conditions.

As for triaxial test, the successful development of laboratory large-scale triaxial testing equipment makes it possible to conduct indoor tests for geomaterials containing coarse grained particles. Moreover, stress state provided by 

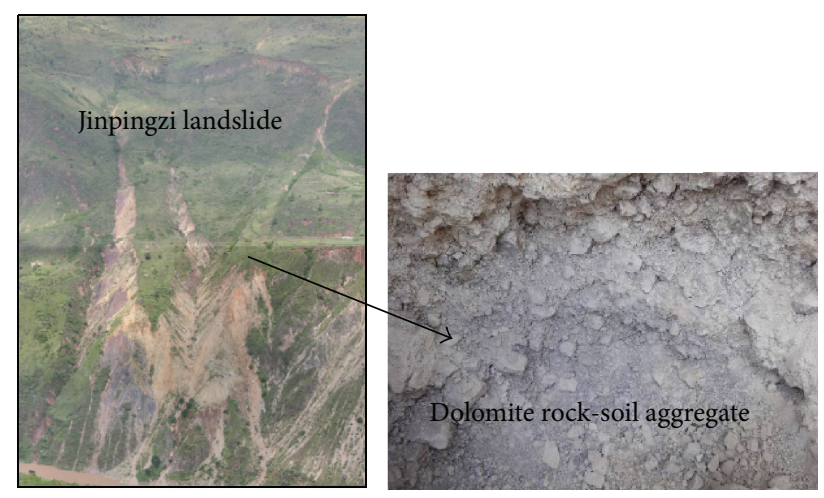

FIGURE 1: Dolomite rock-soil aggregate in Jinpingzi landslide.

large-scale triaxial test is close to real situation and multiple stress paths can be imposed. As a result, the measured parameters are then rational and reliable and can well reflect the inherent features of rock-soil aggregate. So far, researches based on large-scale triaxial test focusing on the mechanical characteristics of rock-soil aggregate sampled from natural sliding mass are rarely reported.

The Jinpingzi landslide took place at Wudongde hydropower plant in Southwest China. The volume of the sliding mass is about $2,700 \times 10^{4} \mathrm{~m}^{3}$ and its thickness is about $45 \sim$ $100 \mathrm{~m}$. It is a deep layer sliding mass whose main contents are ancient gully of gravelly soil and dolomite rock-soil aggregates. The studied dolomite rock-soil aggregates are sampled from this sliding mass (Figure 1). By performing laboratory large-scale triaxial tests, the mechanical characteristics and deformation failure patterns of the rock-soil aggregates are analyzed.

\section{Materials and Methods}

2.1. Materials. The front side of the sliding mass in Jinpingzi landslide is chosen as the sampling area. The obtained sample has rich gradation (Figure 2(a)). Its particles have various shapes, which are mostly angular and subangular. Most rock block size ranges from $2 \mathrm{~cm}$ to $7 \mathrm{~cm}$ and the maximum size reaches $15 \mathrm{~cm}$. The rock-soil aggregates are primarily composed of $\mathrm{Z} 2 \mathrm{~d}$ dolomite and siliceous dolomite, which have high mechanical strength.

Laboratory particle analysis is conducted on the samples of rock-soil aggregate firstly. The equivalent substitution method is employed to reduce the scale of the oversized particles. Particles with a diameter range of $5 \sim 60 \mathrm{~mm}$ are used to equivalently substitute for those oversized particles whose diameter exceeds $60 \mathrm{~mm}$. The proportion of particles whose diameters are less than $5 \mathrm{~mm}$ remains unchanged. The obtained gradation used for test is plotted as the average line in Figure 2(a). Gradations 1, 2, 4, and 5 are adjusted as wide gradation for the test.

\subsection{Large-Scale Triaxial Shear Apparatus and Test Methodolo-} gies. The dimension of the sample is arranged as $\Phi 300 \mathrm{~mm} \times$ $600 \mathrm{~mm}$. The test is conducted on the large-scale triaxial test machine and plotted in Figure 2(b).
The samples used in the triaxial test are in saturation state. At the start of the test, the samples are all restored to their natural stress state. The confining pressures are arranged as $0.4 \mathrm{MPa}, 0.8 \mathrm{MPa}, 1.2 \mathrm{MPa}$, and 1.6 MPa. The densities of saturated samples are obtained by compaction test (Table 1). The compactness degree of all samples is controlled as $90 \%$.

The consolidated-drained triaxial shear test is straincontrolled. The shear velocity is fixed at $0.25 \mathrm{~mm} / \mathrm{min}$ (or $2.5 \% / \mathrm{h}$ ). The sample size, dry density, and gradation are all calculated in accordance with test requirements. The rock-soil aggregate samples are then weighed and mixed uniformly.

\section{Results and Discussions}

3.1. Test Results. Large-scale saturated consolidated-drained shear tests are performed on the prepared samples which are arranged in 5 fixed gradations. The stress to strain curves and volumetric strain to axial strain curves are then obtained. The curves of different gradation samples are plotted in Figures 3 and 4 .

The following findings can be summarized after analyzing the triaxial test results.

(1) Remarkable nonlinearity is observed in the stress to strain curve of rock-soil aggregate samples. The maximum principal difference value, denoted by $\left(\sigma_{1}-\right.$ $\left.\sigma_{3}\right)_{f}$, increases as the confining pressure increases.

(2) When the confining pressure is low $\left(\sigma_{3}=0.4 \mathrm{MPa}\right)$, rock-soil aggregate exhibits slight strain softening effect. The strain-hardening degree increases as the confining pressure increases. When the confining pressure approaches larger value $\left(\sigma_{3}=0.8 \mathrm{MPa}\right)$, rocksoil aggregate takes on strain-hardening effect. The stress-strain curves based on 20 samples all have wide range of approximately horizontal distributions near peak point. This indicates that rock-soil aggregate has remarkable ductile plastic deformation features.

(3) By observing the volumetric strain to axial strain curve, it is found that the shear contraction deformation increases as the confining pressure increases. When the confining pressure is low $\left(\sigma_{3}=0.4 \mathrm{MPa}\right)$, the samples firstly show shear contraction and then show shear dilation. As the confining pressure increases, the degree of shear dilation decreases. When the confining pressure is high $\left(\sigma_{3} \geq 1.2 \mathrm{MPa}\right)$, the samples basically exhibit shear contraction. As the loading increases, the increasing extent of shear contraction deformation becomes smaller.

The above observed macroscopic deformation findings have close relevance to the adjustments of mesoscopic fabric and particle rupture of rock-soil aggregate during loading process. When the confining pressure is low, the resistance against particle movements is small. Therefore, when samples are under shear state, particles are easy to overcome the resistance and turn over adjacent particles, thus causing dislocated slips. As a result, remarkable shear dilation deformation is observed and the strain softening effect of stress to strain 


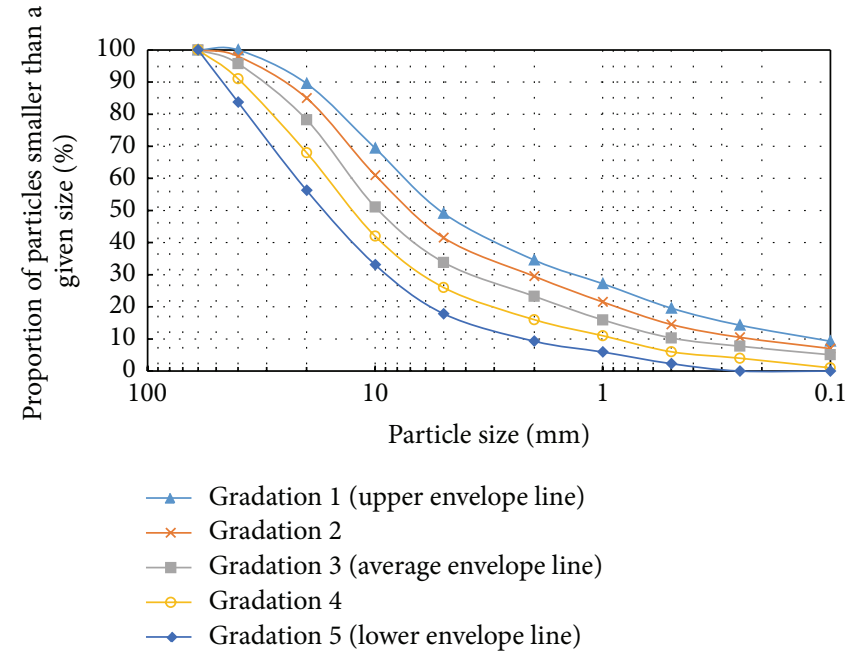

(a)

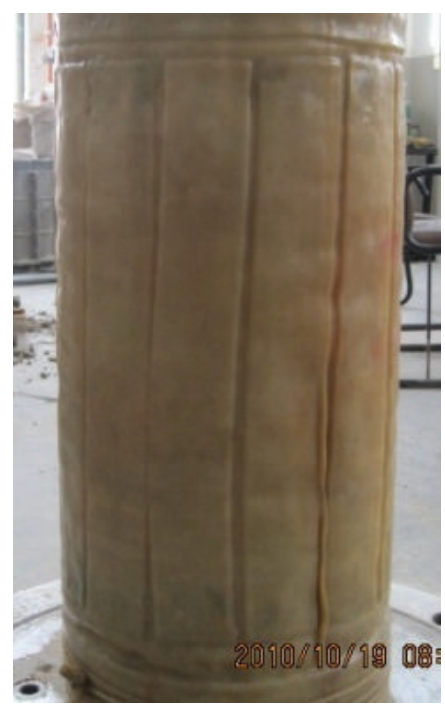

(c)

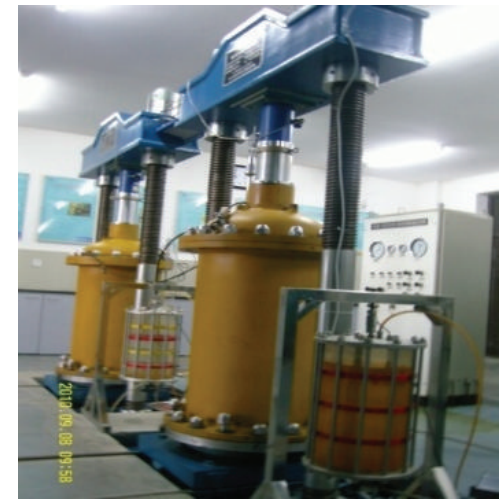

(b)

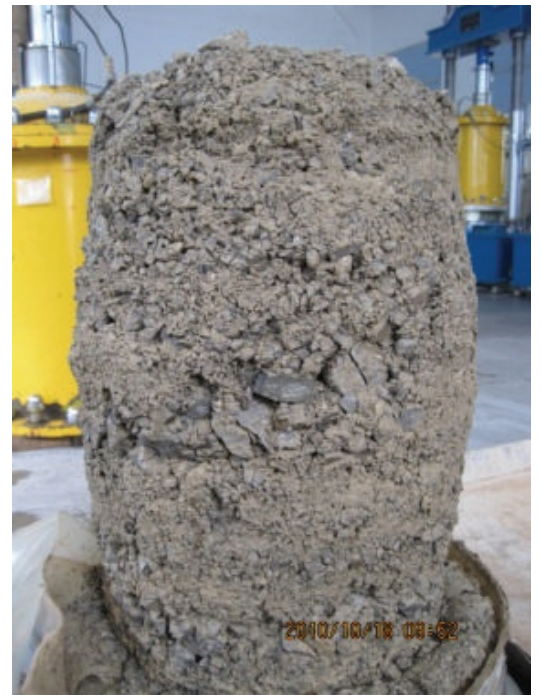

(d)

FIGURE 2: Laboratory triaxial test: (a) gradation of rock-soil aggregate; (b) stress-controlled large-scale triaxial test; (c) test sample of rock-soil aggregate; (d) failure mode.

TABLE 1: Dry density of rock-soil aggregate samples.

\begin{tabular}{|c|c|c|c|c|c|}
\hline Gradation & Gradation 1 & Gradation 2 & Gradation 3 & Gradation 4 & Gradation 5 \\
\hline Dry density $\left(\mathrm{g} / \mathrm{cm}^{3}\right)$ & 2.102 & 2.135 & 2.144 & 2.128 & 2.073 \\
\hline Rock proportion (P5) & $50.89 \%$ & $58.50 \%$ & $66.16 \%$ & $74.00 \%$ & $82.17 \%$ \\
\hline
\end{tabular}

curve is weaker. When the confining pressure is high, the constraining effects among particles and resistance against movements are considerable during shear failure process. Therefore, when samples are under shear state, it is difficult for particles to overcome the resistance, thus lowering the possibility of dislocated slips. As a result, shear dilation degree is lowered. As particles cannot turn over adjacent particles, stress concentration is induced. It then leads to particle ruptures and rearrangements. The stress to strain curve is hardening type and the volumetric strain is primarily condensed.

\subsection{Effects of Gradation and Stone Content}

Stress-Strain Curves. To analyze the differences of deformation features among different samples, the stress to strain curves and volumetric strain to axial strain curves obtained from samples of different gradation groups are plotted in Figures 5 and 6 . The curves are all obtained from tests under the same confining pressure.

It is found from Figures 5 and 6 that, under the same confining pressure, the stress to strain curve obtained from 


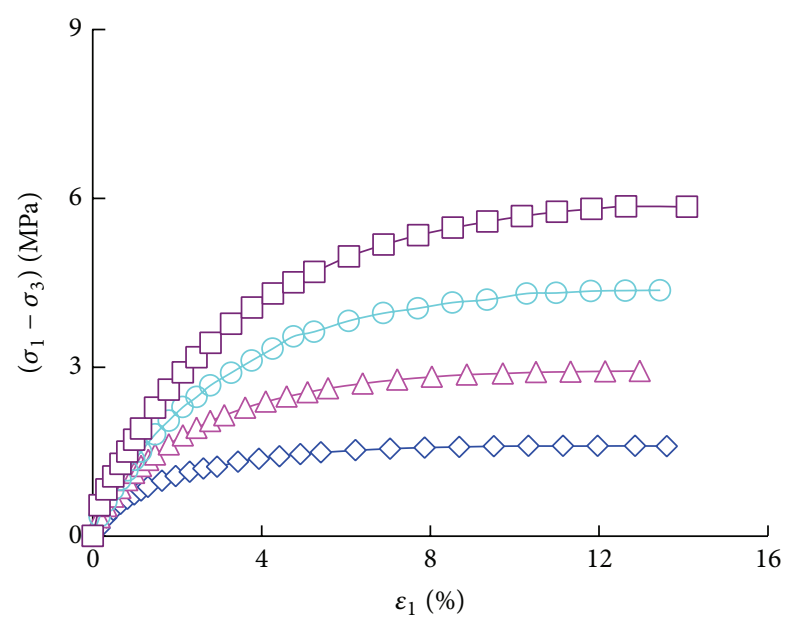

(a)

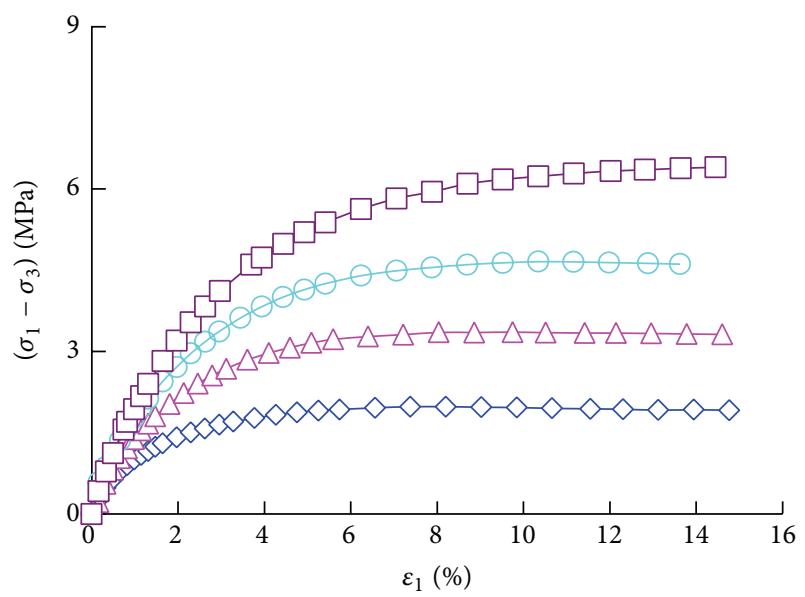

(c)

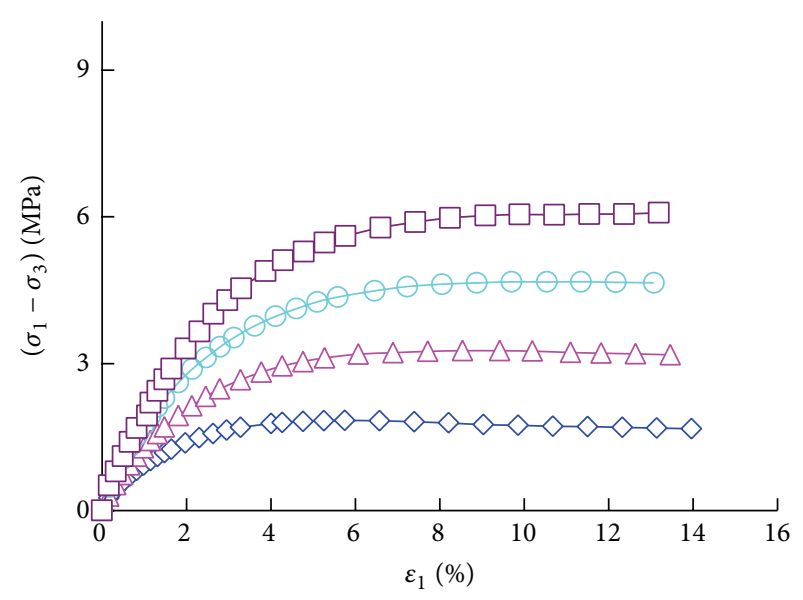

(b)

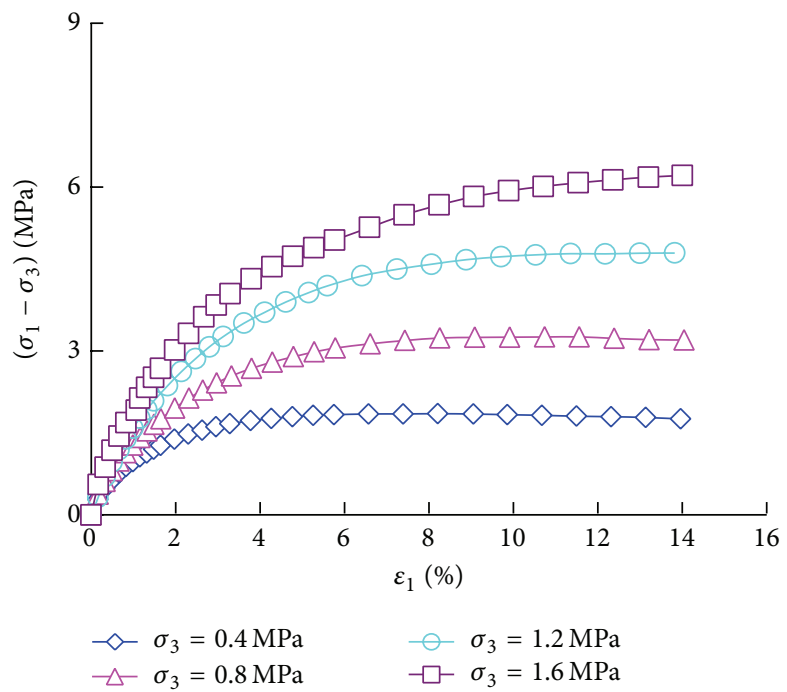

(d)

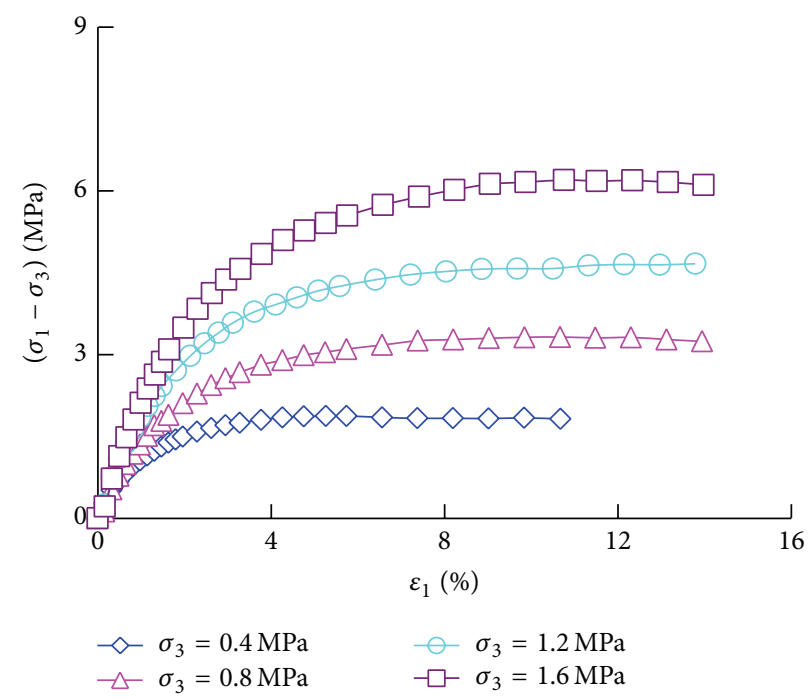

(e)

FIGURE 3: Stress-strain curve under different confining pressure: (a) gradation 1, rock proportion (P5), 50.89\%; (b) gradation 2, rock proportion (P5), 58.50\%; (c) gradation 3, rock proportion (P5), 66.16\%; (d) gradation 4, rock proportion (P5), 74.00\%; (e) gradation 5, rock proportion (P5), $82.17 \%$. 


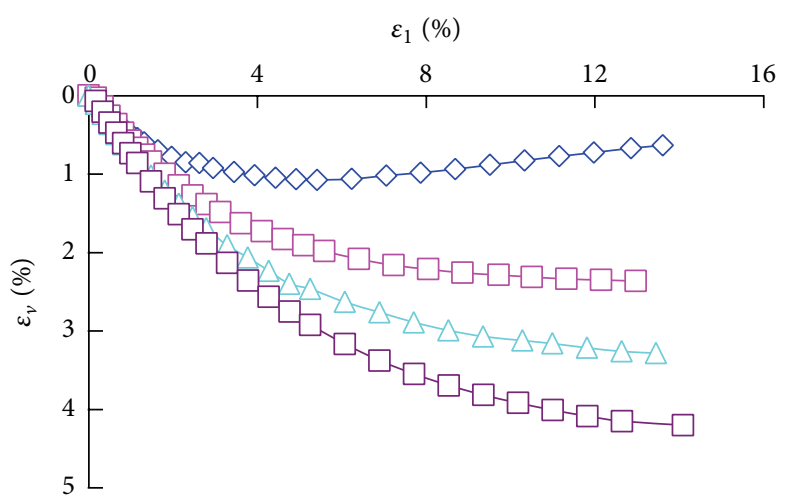

(a)

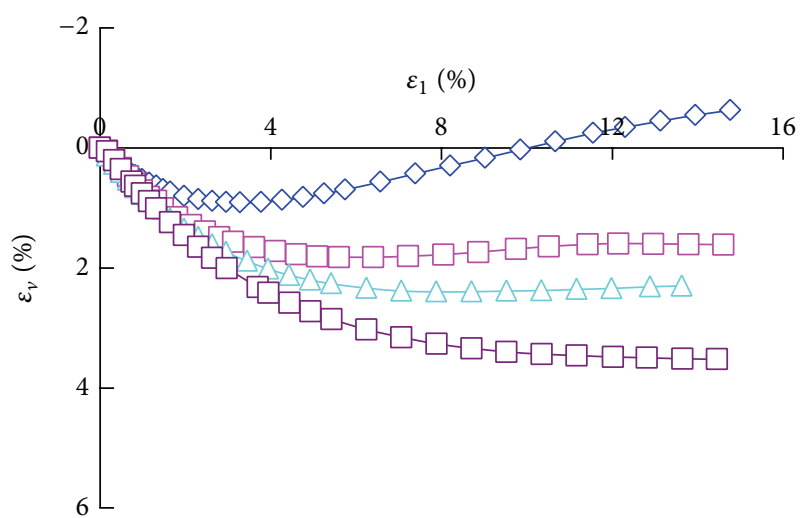

(c)

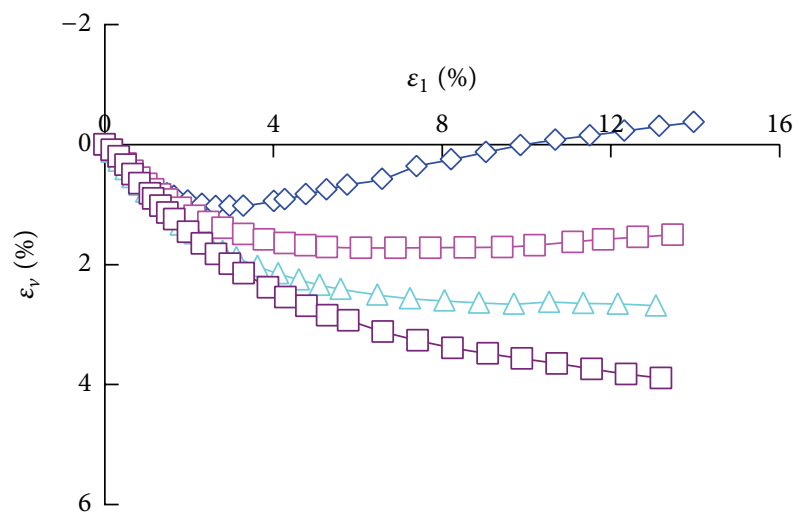

(b)

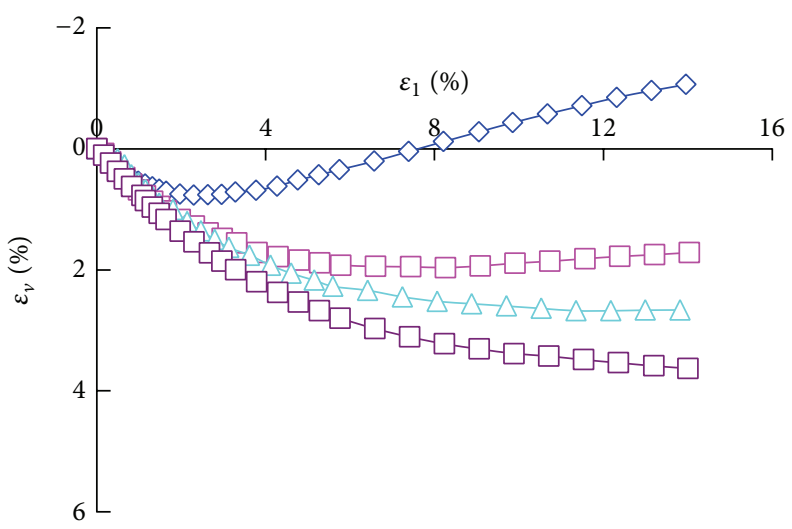

$$
\begin{aligned}
\smile \sigma_{3}=0.4 \mathrm{MPa} & -\square \sigma_{3}=1.2 \mathrm{MPa} \\
-\square \sigma_{3}=0.8 \mathrm{MPa} & \neg \square \sigma_{3}=1.6 \mathrm{MPa}
\end{aligned}
$$

(d)

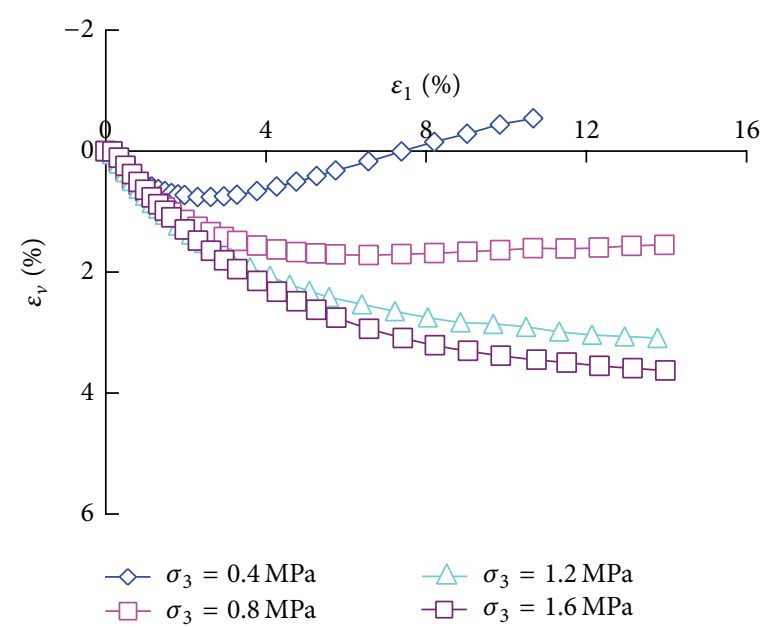

(e)

FIGURE 4: Volumetric strain to axial strain curve under different confining pressure: (a) gradation 1, rock proportion (P5), 50.89\%; (b) gradation 2, rock proportion (P5), 58.50\%; (c) gradation 3, rock proportion (P5), 66.16\%; (d) gradation 4, rock proportion (P5), 74.00\%; (e) gradation 5, rock proportion (P5), 82.17\%. 


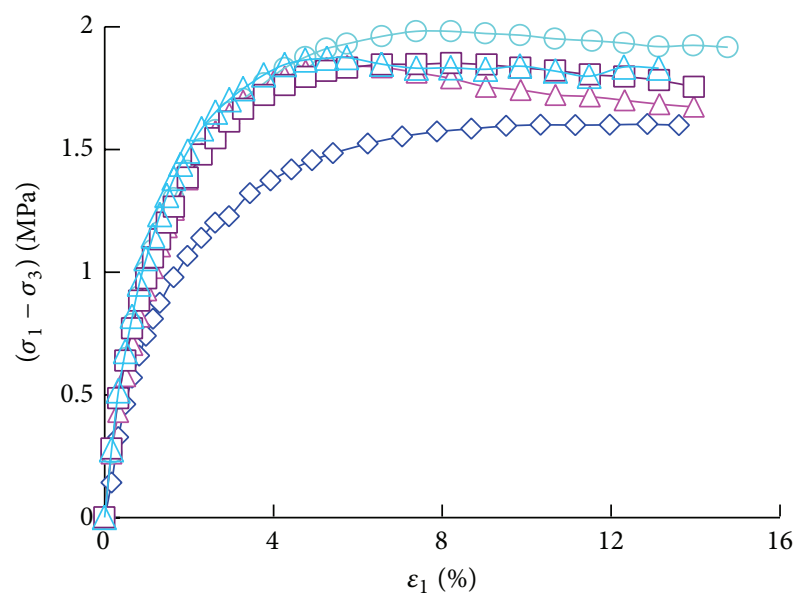

(a)

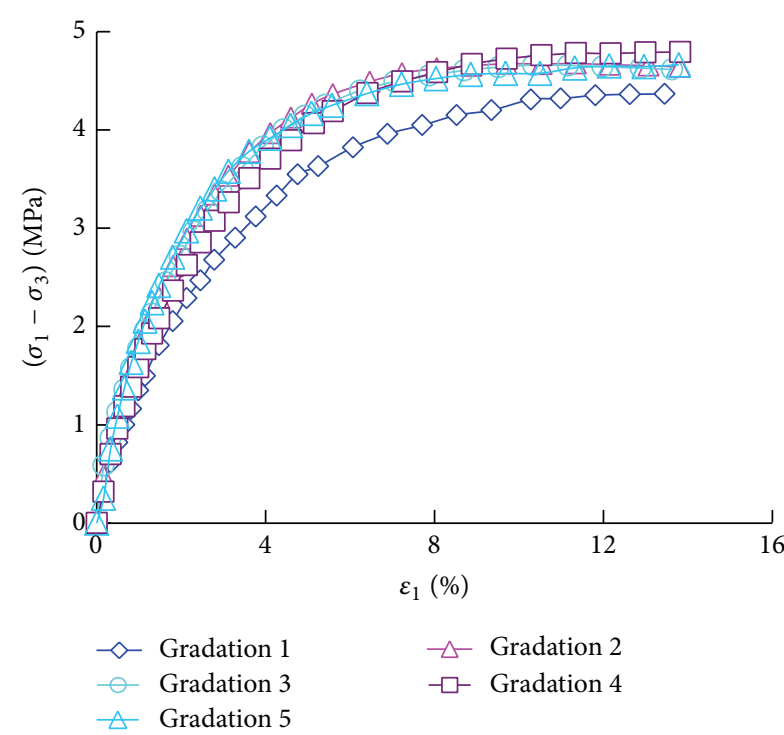

(c)

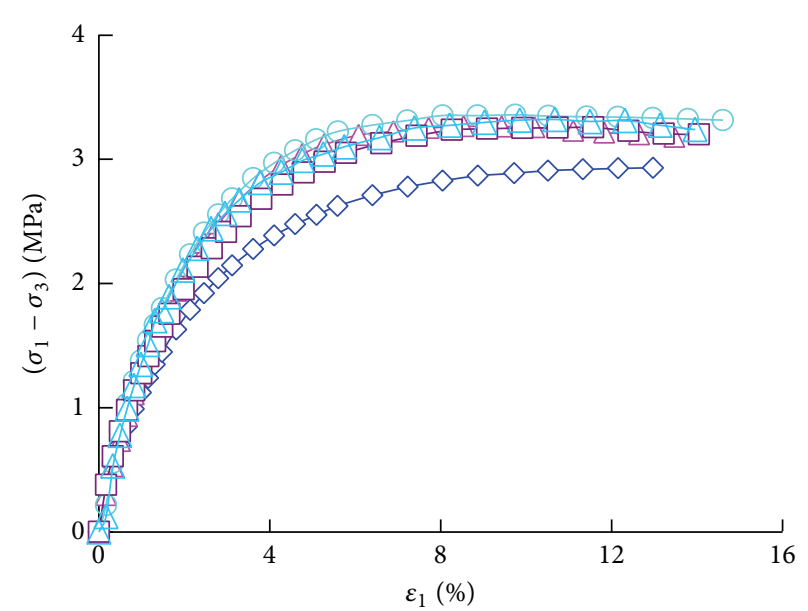

(b)

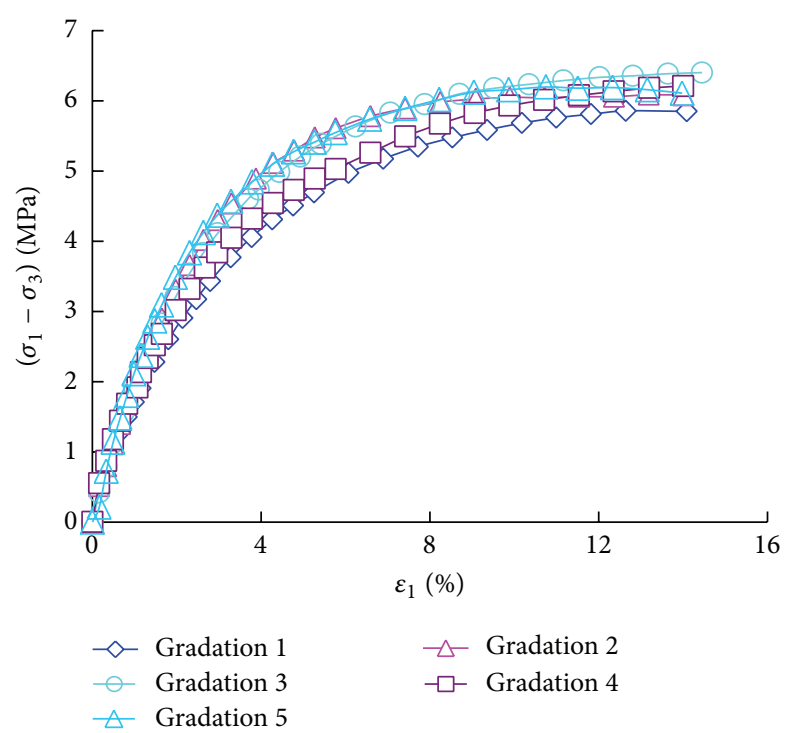

(d)

FIGURE 5: Stress-strain curve under different gradation: (a) $\sigma_{3}=0.4 \mathrm{MPa}$; (b) $\sigma_{3}=0.8 \mathrm{MPa}$; (c) $\sigma_{3}=1.2 \mathrm{MPa}$; (d) $\sigma_{3}=1.6 \mathrm{MPa}$.

gradation number 1 sample is considerably lower with large deviation extent compared to other curves, while other curves obtained from gradation number 2 to number 5 samples are basically identical.

Under low confining pressure, the stress to strain curve of gradation 1 is remarkably lower than curves of gradations $2 \sim 5$. As the confining pressure increases, curve of gradation 1 gradually approaches the curves of other gradations. Under high confining pressure, curve distribution of all gradations is basically similar.

For volumetric strain to axial strain relation, the shear contraction effect of gradation 1 is more observable than other gradations. Particularly for confining pressure lower than $0.4 \mathrm{MPa}$, the volumetric strain of gradations $2 \sim 5$ samples firstly increases and then quickly decreases, turning the volumetric strain magnitude from positive value into negative value. Equally, during the process, shear contraction firstly takes place and then remarkable shear dilation takes place. On the other hand, although the volumetric strain of gradation 1 sample is also firstly increasing and then decreasing, the decreasing speed is lower and volumetric strain magnitude maintains positive value during the whole process. Compared to other gradations, dilation effect of gradation 1 sample is not obvious. As the confining pressure increases, shear dilation effect of all gradations gradually becomes less observable. Particularly, when the confining pressure exceeds $0.8 \mathrm{Mpa}$ for gradation 1, shear contraction effect occurs and shear dilation effect no longer exists. For other gradations under confining pressure of $0.8 \mathrm{Mpa}$, shear contraction effect is also observed and shear dilation effect becomes less observable. When the confining pressure is above 1.2 Mpa, gradations 2 5 samples take on shear contraction effect and shear dilation effect no longer existed. In a word, under high confining pressure, the volumetric strain to axial strain curves 


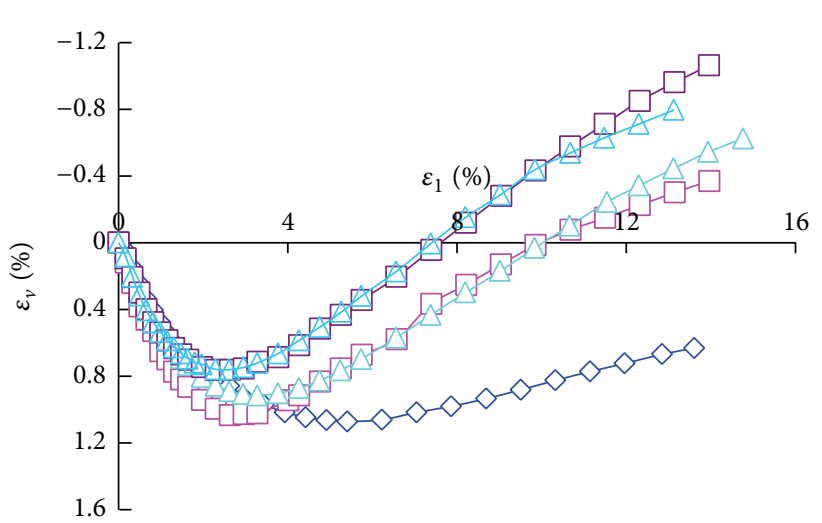

(a)

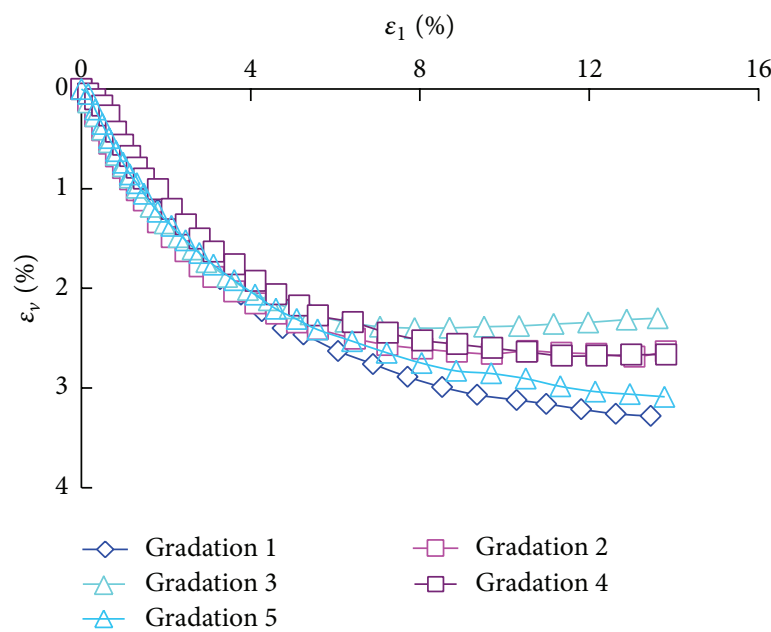

(c)

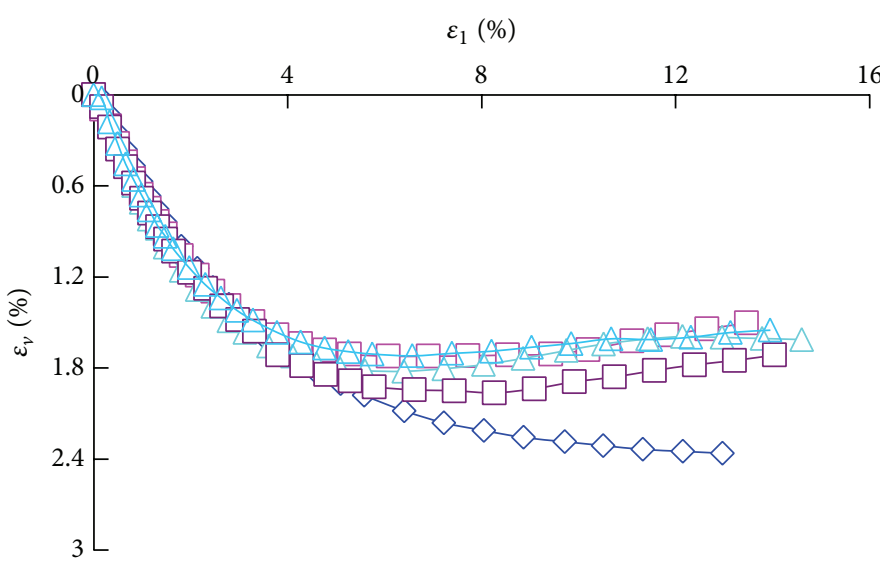

(b)

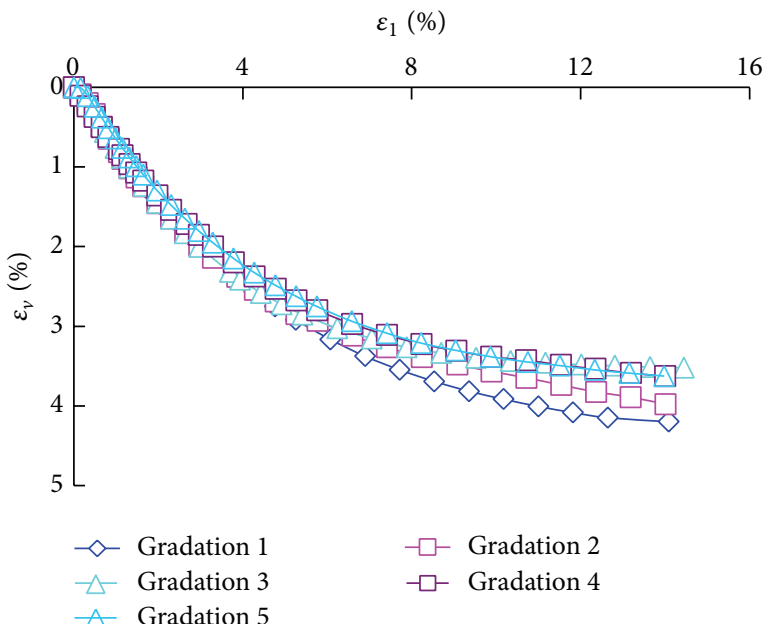

(d)

FIGURE 6: Volumetric strain to axial strain curve under different gradation: (a) $\sigma_{3}=0.4 \mathrm{MPa}$; (b) $\sigma_{3}=0.8 \mathrm{MPa}$; (c) $\sigma_{3}=1.2 \mathrm{MPa}$; (d) $\sigma_{3}=$ $1.6 \mathrm{MPa}$.

of all gradations are observed to distribute uniformly. This feature is basically consistent with that of stress to strain curves.

The reason is that the proportion of fine grained particle with diameters smaller than $5 \mathrm{~mm}$ accounts for $49.11 \%$. Therefore, the skeleton effect provided by coarse grained particles is not obvious. On the other hand, the rock proportion ranges from $60 \%$ to $80 \%$ in gradation number 2 to number 5 samples. Coarse and fine grained particles can attain fully mutual contact. Coarse grained particles can form skeletons and fine grained particles can fully fill the voids inside skeletons, thus making it possible to reach an optimum composition and produce considerable bite force. Therefore, the deviatoric stress is larger. From the start of loading to the arrival of maximum loading value, the stress to strain curves of gradations number 2, number 3, and number 4 almost coincide with that of gradation number 5 . It indicates that when rock proportion ranges from $60 \%$ to $80 \%$, its variation has small influences on the stress to strain curves before reaching the maximum value. After reaching the maximum loading value, the stress to strain curves develop dispersedly. As the composition of coarse and fine particles of gradation number 3 sample reaches optimal state, the maximum deviatoric stress is observed. When the confining stress is low, the volumetric strain curves of all samples exhibit remarkable shear contraction (or shear dilation) characteristics.

Shear Strength Parameters. It is observed that the strength envelope lines are typically linear under the condition of confining pressure 0.4 MPa 1.6 Mpa (Figure 7). Mohr-Coulomb failure criterion has been adopted for determining shear strength parameters $c$ and $\varphi$. The variation laws of shear strength parameters $c$ and $\varphi$ with the variation of rock proportion are plotted in Figure 8 and given in Table 2.

With the increase of the amount of stone, values of shear strength parameter $\varphi$ of different sample gradations show a slowly increasing trend but values of shear strength parameter $c$ show a slowly downward trend. For no sticky granular medium such as rock-soil aggregate, its shear strength is primarily provided by the bite forces among particles. As the voids inside coarse particles of gradation number 3 


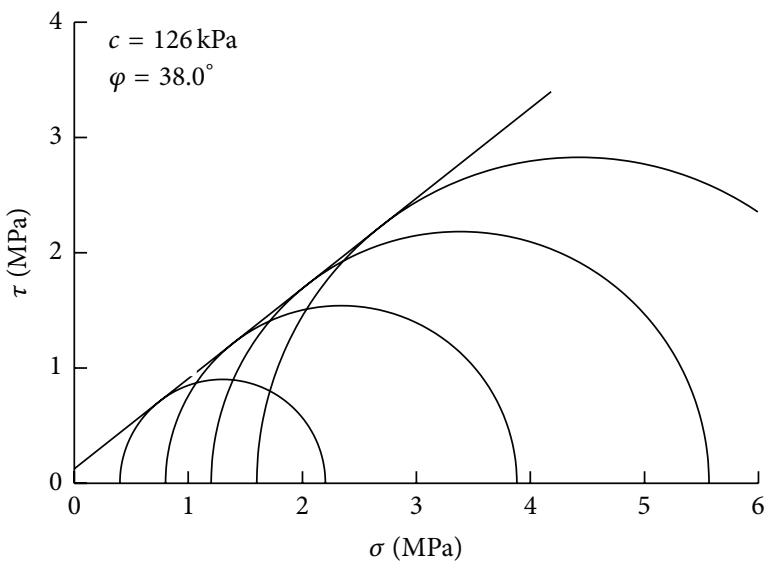

(a)

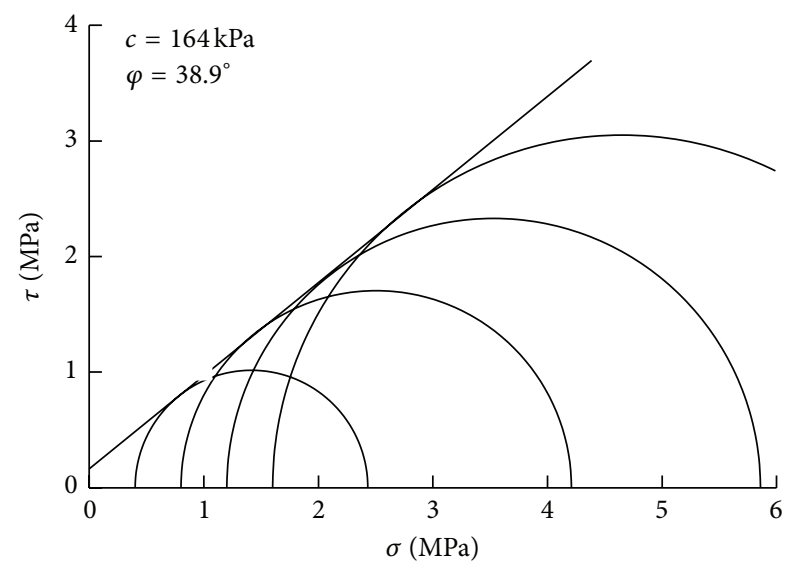

(b)

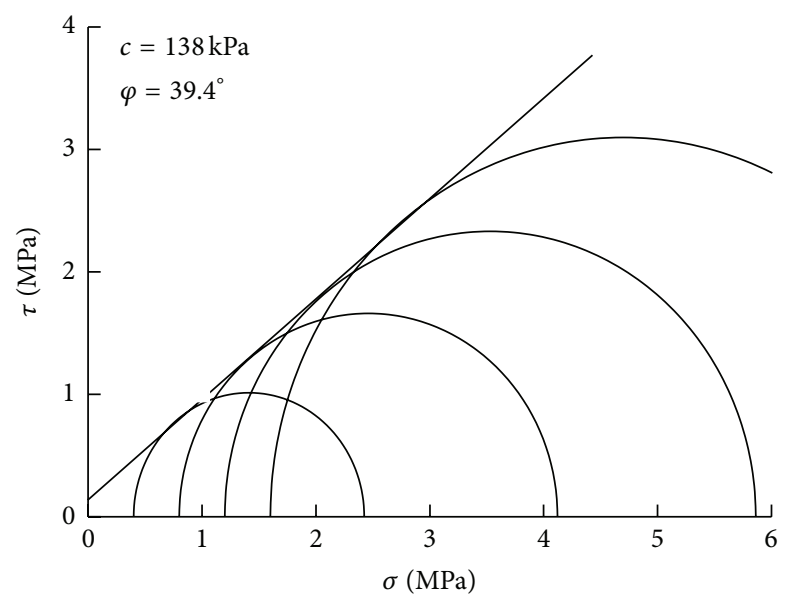

(c)

FIgURE 7: Mohr-Coulomb failure envelopes and Mohr circles: (a) gradation 1; (b) gradation 3; (c) gradation 5.

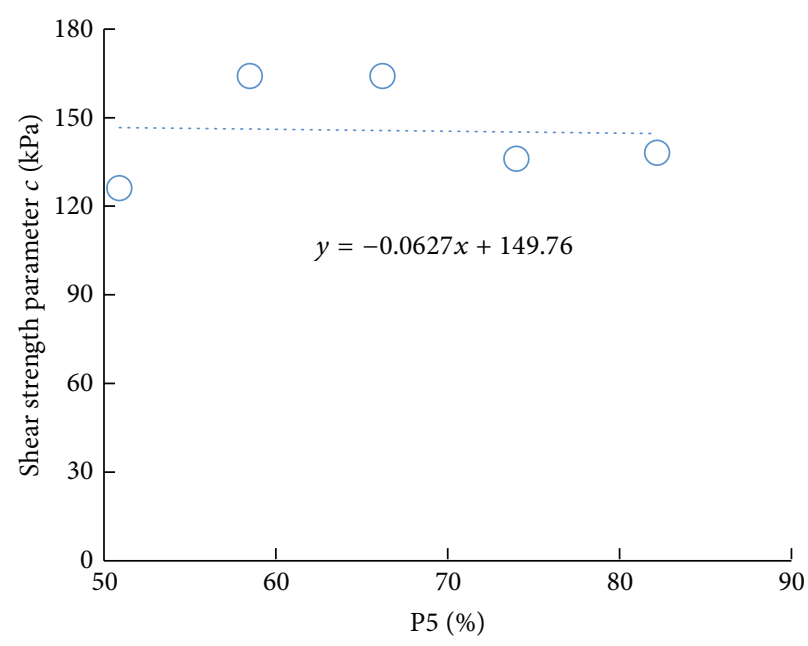

(a)

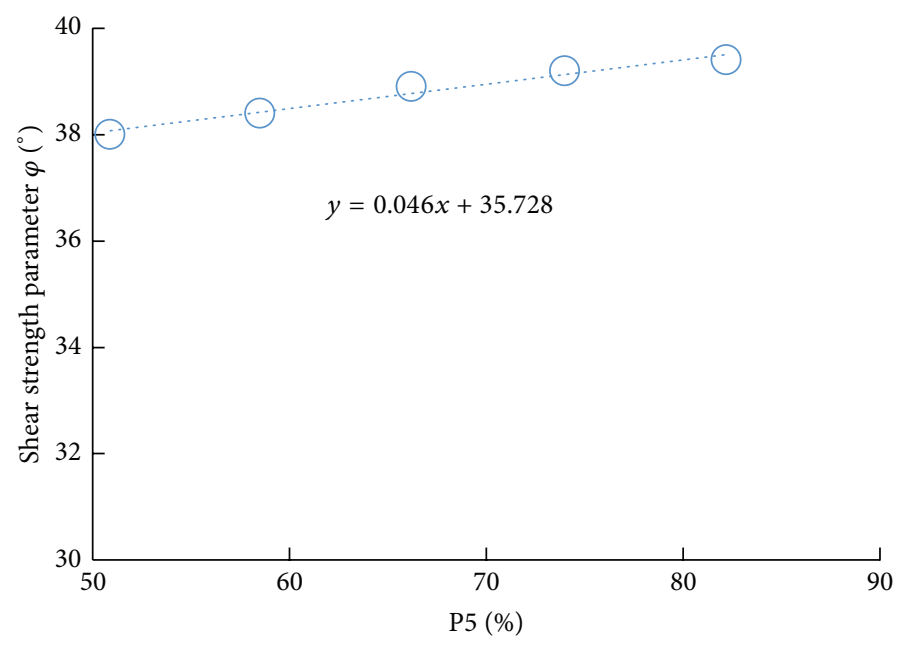

(b)

FIGURE 8: Shear strength parameters to rock proportion curve: (a) shear strength parameter $c$; (b) shear strength parameter $\varphi$. 
TABLE 2: Parameters of Duncan-Chang model, including $E-B$ model and $E-\mu$ model.

\begin{tabular}{lcccccccccc}
\hline P5/\% & $c / \mathrm{MPa}$ & $\Phi /^{\circ}$ & $K$ & $n$ & $K_{b}$ & $m$ & $R_{f}$ & $G$ & $F$ & $D$ \\
\hline 50.9 & 126 & 38.0 & 919 & 0.333 & 355 & 0.284 & 0.869 & 0.435 & 0.238 & 4.303 \\
58.5 & 164 & 38.4 & 1009 & 0.394 & 456 & 0.295 & 0.830 & 0.295 & 0.138 & 5.760 \\
66.2 & 164 & 38.9 & 1076 & 0.376 & 470 & 0.274 & 0.845 & 0.351 & 0.178 & 5.618 \\
74 & 136 & 39.2 & 1100 & 0.314 & 493 & 0.232 & 0.825 & 0.360 & 0.155 & 4.542 \\
82.2 & 138 & 39.4 & 1094 & 0.347 & 455 & 0.337 & 0.814 & 0.256 & 0.054 & 5.742 \\
\hline
\end{tabular}

and number 4 samples can be well filled by fine particles and meanwhile coarse particles can mutually form favorable skeletons, the bite forces of these two samples can reach maximum value. As the rock proportions of gradation number 4 and number 5 samples are comparatively larger, the coarse and fine particles are able to contact closely. Therefore, their bite forces and shear strength are also considerable. The proportion of fine particles in gradation number 1 samples is comparatively larger than other samples; thus its shear strength is smaller. The shear strength parameter $\varphi$ ranges from $38.0^{\circ}$ to $39.4^{\circ}$, which is not remarkably affected by P5.

Deformation Parameters. As mentioned above, rock-soil aggregate behaves highly nonlinearly. A hyperbolic model known as Duncan-Chang model is an incremental nonlinear stress-dependent model which is suggested by Duncan and Chang [13]. Mohr-Coulomb is its failure criteria which includes two strength parameters $c$ and $\varphi$. This model including $E-\mu$ mode and $E-B$ model describes nonlinearity and stress-dependent and inelastic behavior. Tangential elastic modulus and tangential Poisson's ratio can be described using expressions proposed by $E-\mu$ model as follows [13]:

$$
\begin{gathered}
E_{t}=E_{i}\left[1-\frac{R_{f}\left(\sigma_{1}-\sigma_{3}\right)(1-\sin \varphi)}{2 c \cos \varphi+2 c \sigma_{3} \sin \varphi}\right]^{2}, \\
\mu_{t}=\frac{\mu_{i}}{(1-A)^{2}}, \\
A=D\left(\sigma_{1}-\sigma_{3}\right)\left(K p_{a}\left(\frac{\sigma_{3}}{p_{a}}\right)\right. \\
\left.\times\left[1-\frac{R_{f}\left(\sigma_{1}-\sigma_{3}\right)(1-\sin \varphi)}{2 c \cos \varphi+2 c \sigma_{3} \sin \varphi}\right]\right)^{-1},
\end{gathered}
$$

where $c$ is cohesion and $\varphi$ is internal friction angle. $R_{f}$ is the principal stress ratio when failure occurs. $D$ is the lateral expansive strain increment induced by deviatoric stress increment.

Moreover, when $E-B$ model is used, bulk modulus $B_{t}$ of rock-soil aggregate can be calculated by [14]

$$
B_{t}=K_{b} p_{a}\left(\frac{\sigma_{3}}{p_{a}}\right)^{m},
$$

where $K_{b}$ is the ratio of initial bulk modulus to $P_{a}$ when confining pressure is normal atmosphere. $m$ is an index describing the increasing extent of bulk modulus as confining pressure increases.
The relationship between initial elastic modulus $E_{i}$ and confining pressure, as well as the relationship between initial Poisson's ratio $\mu_{i}$ and confining pressure, is given in Figure 9. It is found that as the confining pressure increases, the initial elastic modulus increases too. As $\lg \left(E_{i}\right)$ and $\lg \left(\sigma_{3} / P_{a}\right)$ are linearly related, the relationship between $E_{i}$ and confining pressure can be described as a stress-dependent parameter using a power law formulation suggested by Janbu [15]:

$$
E_{i}=K P_{a}\left(\frac{\sigma_{3}}{P_{a}}\right)^{n},
$$

where $P_{a}$ is normal atmosphere and $K$ is the ratio of $E_{i}$ to $P_{a}$ when the confining pressure is normal atmosphere. $n$ is an index describing the increasing extent of $E_{i}$ when confining pressure increases.

It is also found from Figure 9 that the initial Poisson's ratio $\mu_{i}$ decreases as the confining pressure increases and is linearly related to $\lg \left(\sigma_{3} / P_{a}\right)$ as

$$
\mu_{i}=G-F \lg \left(\frac{\sigma_{3}}{P_{a}}\right),
$$

where $G$ is the initial tangential Poisson's ratio under normal atmosphere. $F$ is an index describing the increasing extent of tangential Poisson's ratio when confining pressure increases.

It is found that the axial stress-strain curve of rocksoil aggregate under medium and high confining pressure is nonlinear and can be described using hyperbolic curve, from Figure 10.

The relationship between deformation parameters and stone content P5 is given in Table 2 on the basis of (1) (4). With the increase of stone content P5, deformation parameters $K, K_{b}$, and $D$ generally increase. This indicates that higher value of stone content leads to stronger framework supporting effect produced by coarse grained particles and larger bulk modulus. The values of $G$ and $F$ are both decreasing as $\mathrm{P} 5$ increases. The values of $m, n$, and $R_{f}$ are not remarkably affected by $\mathrm{P} 5$.

Internal Friction Angle. The index of internal friction angle of rock-soil aggregate is related to gradation, stone content, and other factors. The cohesion of the sampled sliding mass is assumed zero. Then the internal friction angle $\varphi$ can be obtained using

$$
\varphi=\sin ^{-1} \frac{\sigma_{1}-\sigma_{3}}{\sigma_{1}+\sigma_{3}}
$$

where $\sigma_{1}$ and $\sigma_{3}$ are measured value of the first and the third principal stress in test. The relationship between $\varphi$ and 


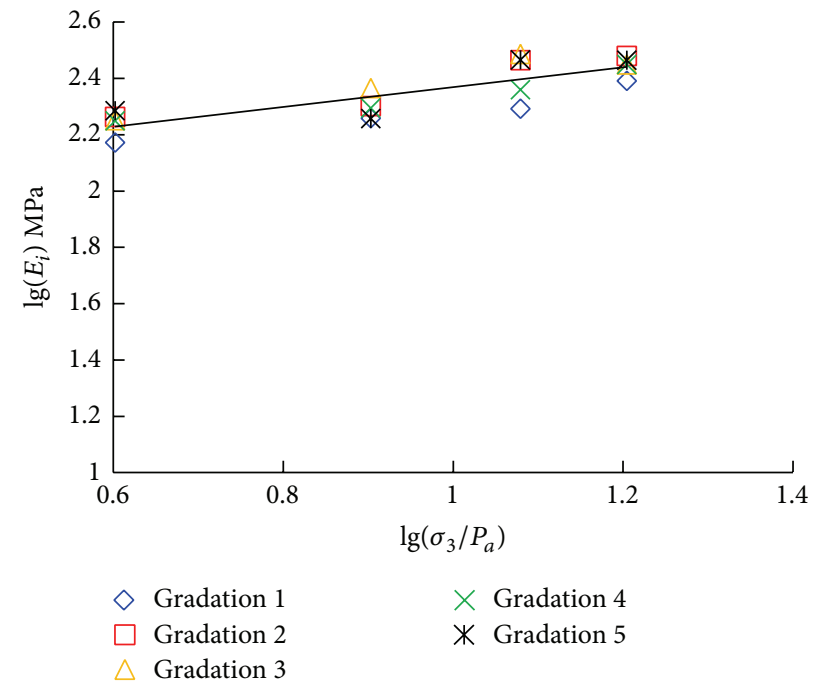

(a)

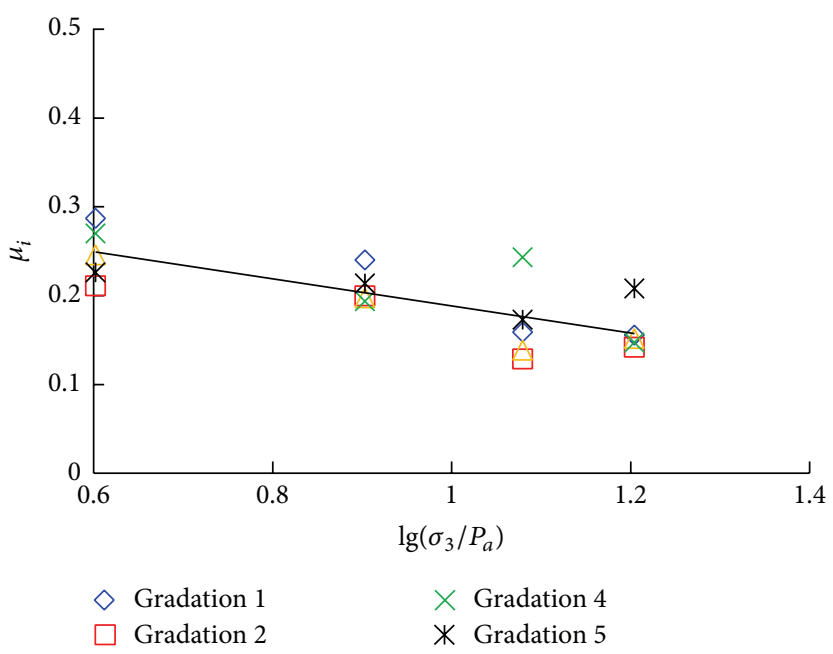

(b)

FIGURE 9: Influence of confining pressure on initial deformation modulus and Poisson's ratio in initial loading stage: (a) initial deformation modulus; (b) initial Poisson's ratio.

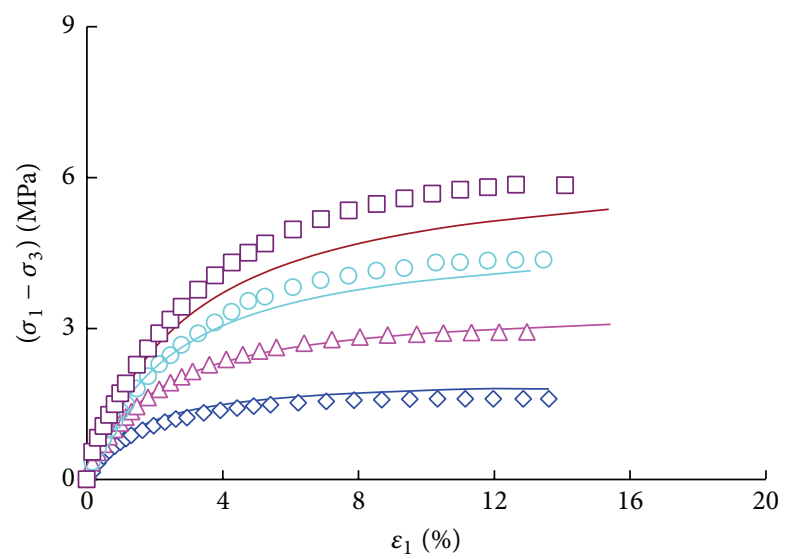

(a)

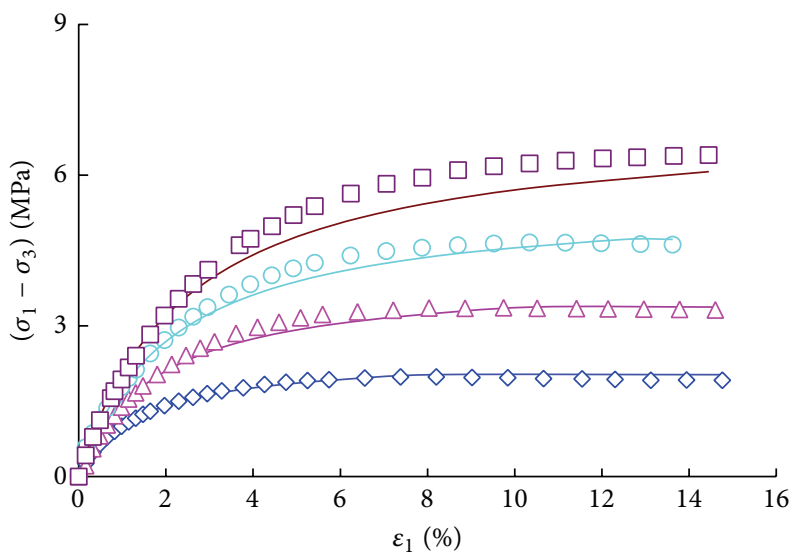

(b)

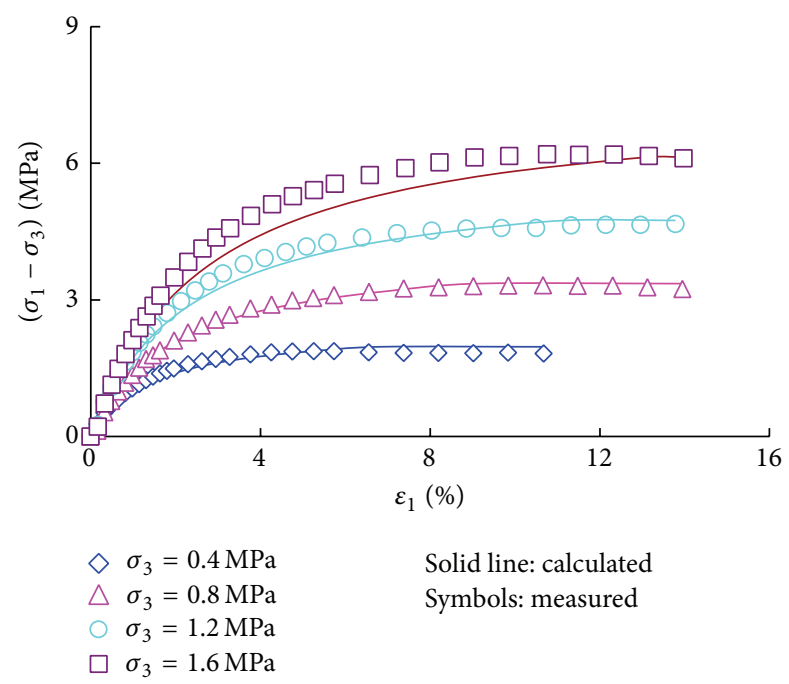

(c)

FIGURE 10: Stress difference versus axial strains: (a) gradation 1; (b) gradation 3; (c) gradation 5. 


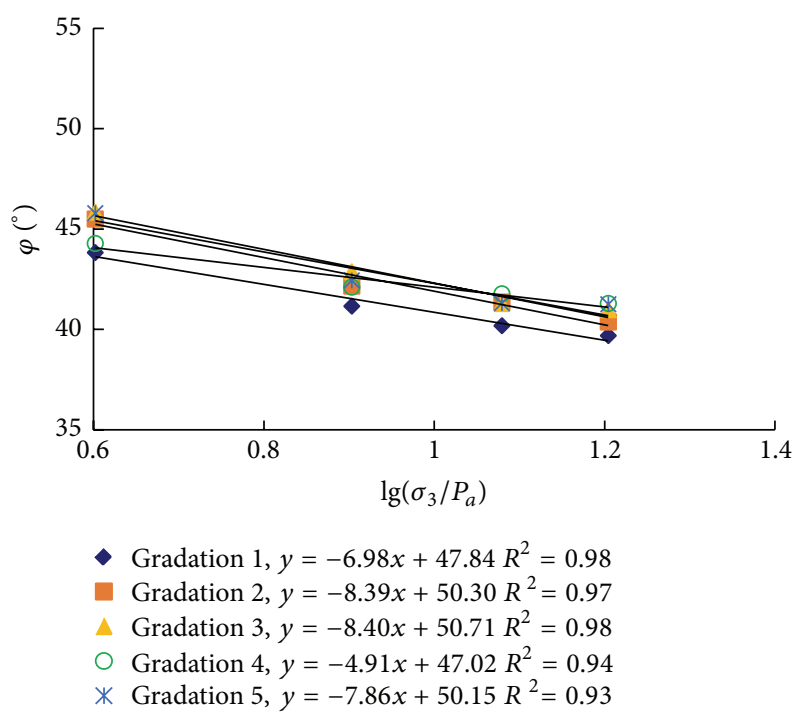

FIGURE 11: Influence of confining pressure on the angle of internal friction.

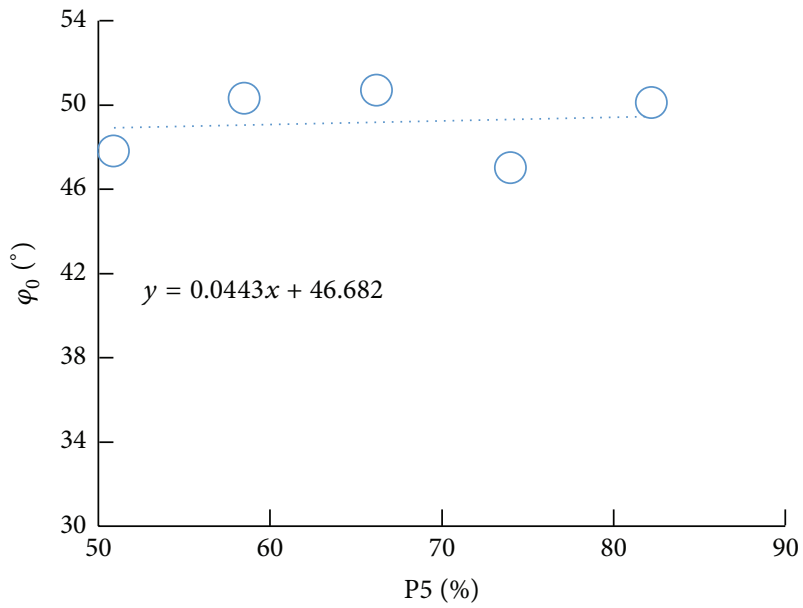

(a)

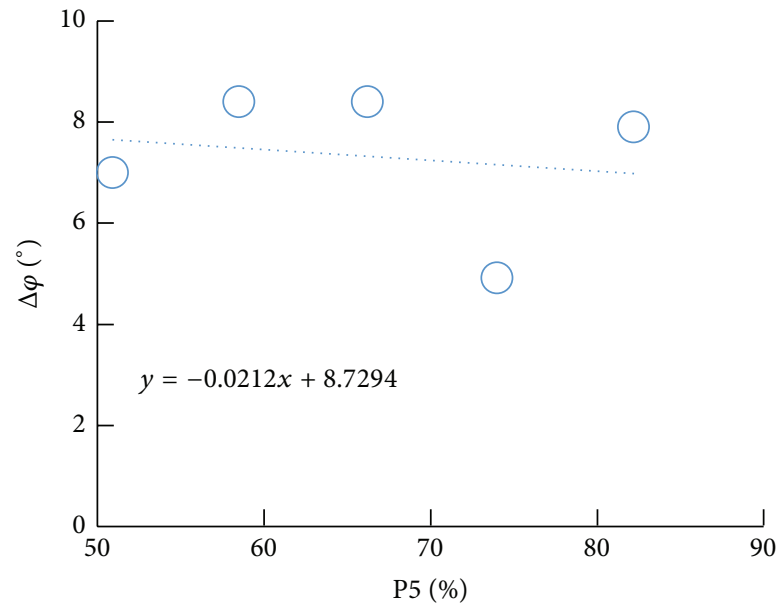

(b)

FIGURE 12: Internal friction angle to rock proportion curve: (a) internal friction angle when confining pressure equals normal atmosphere; (b) gradual decrement of internal friction angle.

confining pressure is given in Figure 11. It is found from Figure 11 that, as the increase of confining pressure, the internal friction angle gradually decreases and is basically log-linearly related to confining pressure as

$$
\varphi=\varphi_{0}-\Delta \varphi \lg \left(\frac{\sigma_{3}}{P_{a}}\right),
$$

where $\varphi_{0}$ is internal friction angle when confining pressure is normal atmosphere. $\Delta \varphi$ is gradual decrement of internal friction angle. When confining pressure is low, internal friction angle reaches its maximum. Based on (5) and (6), the fitted values of $\varphi_{0}$ and $\Delta \varphi$ are shown in Figure 11. The variation of these values with stone content is given in Figure 12. It is found that, in general, $\varphi_{0}$ and $\Delta \varphi$ show gradual increasing trend as stone content increases. When stone content varies within $50 \%$ to $80 \%$, the value of $\varphi_{0}$ ranges from $47^{\circ}$ to $51^{\circ}$ and $\Delta \varphi$ ranges from $4.9^{\circ}$ to $8.5^{\circ}$, indicating that stone content variation does not have significant influences on the values of $\varphi_{0}$ and $\Delta \varphi$. The variation law of peak internal friction angle $\varphi$ as confining pressure varies, presented in the above expression, is suitable for rock-soil aggregate sampled from natural sliding mass.

3.3. Stress-Dilatancy Behavior of Rock-Soil Aggregate. Charles and Watts' research [16] indicates that when principal stress reaches its maximum, dilation rate, namely $\left(d \varepsilon_{v} / d \varepsilon_{1}\right)_{p}$, is related to the maximum value of ratio of the first principal stress to the third principal stress, namely $\left(\sigma_{1} / \sigma_{3}\right)_{p}$. Here, the peak dilation coefficient is defined by the expression $D_{p}=1-\left(d \varepsilon_{v} / d \varepsilon_{1}\right)_{p}$. According to Indraratna's study [17], the hyperbolic curve is recommended to describe this relationship between $\left(\sigma_{1} / \sigma_{3}\right)_{p}$ and $\left(d \varepsilon_{v} / d \varepsilon_{1}\right)_{p}$, based on the 
TABLE 3: Parameters of stress-dilatancy equation.

\begin{tabular}{lccccc}
\hline \multicolumn{3}{c}{ P5/\% } & \multicolumn{2}{c}{$\begin{array}{c}\text { Rowe's stress-dilatancy } \\
\text { equation }\end{array}$} & \multicolumn{3}{c}{ Modified Rowe's } \\
& $1 / K$ & $K$ & $\alpha$ & $\beta$ & $R_{d}$ \\
\hline 50.9 & 0.1933 & 5.17 & 0.1027 & 1.4462 & 4.82 \\
58.5 & 0.1836 & 5.45 & 0.0542 & 1.8047 & 5.03 \\
66.2 & 0.1826 & 5.48 & 0.0516 & 1.8165 & 5.11 \\
74 & 0.1904 & 5.25 & 0.0716 & 1.6493 & 4.95 \\
82.2 & 0.1819 & 5.50 & 0.0453 & 1.9152 & 5.03 \\
\hline
\end{tabular}

condition that the confining pressure ranges from $1 \mathrm{kPa}$ to $240 \mathrm{kPa}$. Rowe proposed the linear stress-dilatancy equation $[18,19]$. Based on the assumption of rigid plastic of rock-soil aggregate, the equation is written as [18]

$$
R=K D \quad \text { or } \quad D=\frac{R}{K},
$$

where $R$ is the principal stress ratio and is calculated by $\sigma_{1} / \sigma_{3}$, $D$ is dilation coefficient and is calculated by $1-\left(d \varepsilon_{v} / d \varepsilon_{1}\right)$, and $K$ is related to an angle of friction. Figure 13 shows the fitting results of $D \sim R$ for all samples with different gradations. According to the test results (Table 3 ), the value of $K$ for rock-soil aggregate ranges from 5.17 to 5.50, indicating that stone content variation does not have significant influences. Also, it is obvious from Figure 13 that Rowe's stress-dilatancy equation obviously overestimated the dilatancy of rock-soil aggregate, and the stress-dilatancy behavior does not have significant influences on the stress level.

From another point of view, it is found from Figure 13(a) that when the confining pressure ranges from $0.4 \mathrm{MPa}$ to 1.6 $\mathrm{MPa}, R$ exhibits a power function relationship with $D$ for all samples with different gradations. In order to model the dilatancy during deformation of rock-soil aggregate, the modified stress-dilatancy relationship becomes

$$
D=\alpha R^{\beta}
$$

where $\alpha$ and $\beta$ are parameters obtained in tests. Let $\alpha=$ $\left(1 / R_{d}\right)^{\beta}$; then $(8)$ can be written as

$$
D=\left(\frac{R}{R_{d}}\right)^{\beta} .
$$

Obviously, the value of $\beta$ reflects the influence of the stress ratio $R$ on the dilatancy of rock-soil aggregate. Particularly, when $\beta=1,(9)$ is the original Rowe's stress-dilatancy equation, and at this time $R_{d}=K$.

Figure 13 shows that the modified stress-dilatancy equation can be used to describe the volume deformation characteristics of rock-soil aggregate. The values of $\beta$ and $R_{d}$ under different gradations are given in Table 3, in which the value of $R_{d}$ for rock-soil aggregate ranges from 4.82 to 5.11 , indicating that rock content variation does not have significant influences. The value of $\beta$ ranges from 1.4462 to 1.9152 , which implied that the $\beta$ value is affected by rock content variation, which mainly shows that when the rock content variation is low, the $\beta$ value is small; when the rock content variation is higher, $\beta$ value is larger.

Figure 14 shows the dilatancy-contraction relationship of rock-soil aggregate expressed by formula (9). Under the low confining pressure condition, when $R<R_{d}$, rock-soil aggregate shows shear contraction; when $R>R_{d}$, the rocksoil aggregate shows shear dilatancy; when $R=R_{d}, d \varepsilon_{v} / d \varepsilon_{1}$ is equal to 0 . So formula (9) inherently assumes that the $R_{d}$ value of rock-soil aggregate not only is the demarcation point of contraction and dilatancy but also is stress ratio of critical state corresponding to constant volume deformation. Under high confining pressure, $R$ is always smaller than $R_{d}$ and contraction occurs for rock-soil aggregate. When $R$ becomes larger and approaches $R_{d}$, rock-soil aggregate gradually comes to critical state and remains constant volume deformation.

\section{Conclusions}

The following understandings can be noted after we analyzed the loading test results of rock-soil aggregate derived from Jinpingzi sliding mass.

(1) Under the confining pressure of $0.4 \mathrm{MPa}$, rock-soil aggregate exhibits slight strain softening effect and remarkable shear dilation effect. When confining pressure exceeds $0.8 \mathrm{MPa}$, the sample exhibits strainhardening effect and shear contraction effect. Under low confining pressure condition, the variation of stone content and gradation has significant influences on stress-strain curve and volumetric strain-axial strain curve. However, under high confining pressure condition, stress-strain curves and volumetric strainaxial strain curves of different gradations and stone contents are basically similar, indicating that the influences of gradation and stone content are smaller. In general, rock-soil aggregate sampled from sliding mass has both high bearing capacity and considerable ductile plastic deformation characteristics.

(2) Initial elastic moduli $\lg \left(E_{i}\right)$ and $\lg \left(\sigma_{3} / P_{a}\right)$ are linearly related. Initial Poisson's ratio and $\lg \left(\sigma_{3} / P_{a}\right)$ are negatively linearly related. When confining pressure varies within medium and high values, hyperbolic curve can be used to describe the axial stress-strain relation of rock-soil aggregate. When confining pressure ranges from $0.4 \mathrm{MPa}$ to $1.6 \mathrm{MPa}$, the Mohr strength envelope line is typical linear style. When stone content ranges from $50 \%$ to $80 \%$, shear strength parameter $\varphi$ obtained from Mohr-Coulomb strength criterion gradually increases and shear strength parameter $c$ gradually decreases as stone content increases. Internal friction angle is in negative linear relation to $\lg \left(\sigma_{3} / P_{a}\right)$. Their relationship can be described using the Duncan proposed expression. Moreover, under low confining pressure, the internal friction angle reaches its maximum value. This index also maintains large magnitude with high stone content and favorable gradation. 


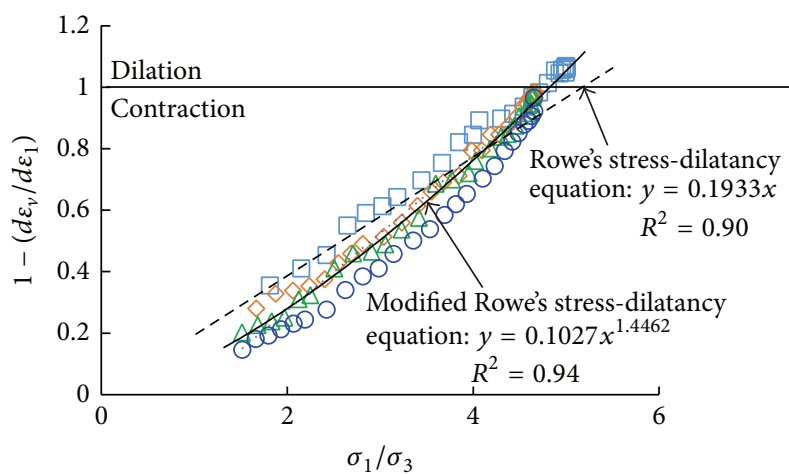

(a)

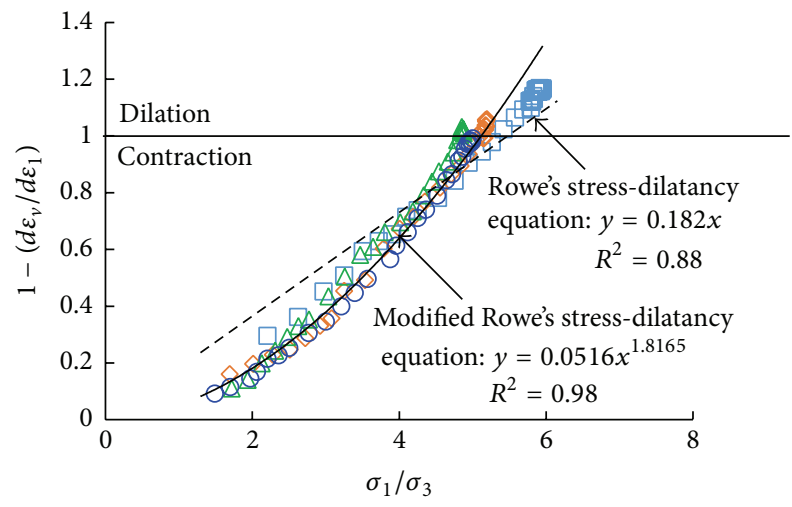

(c)

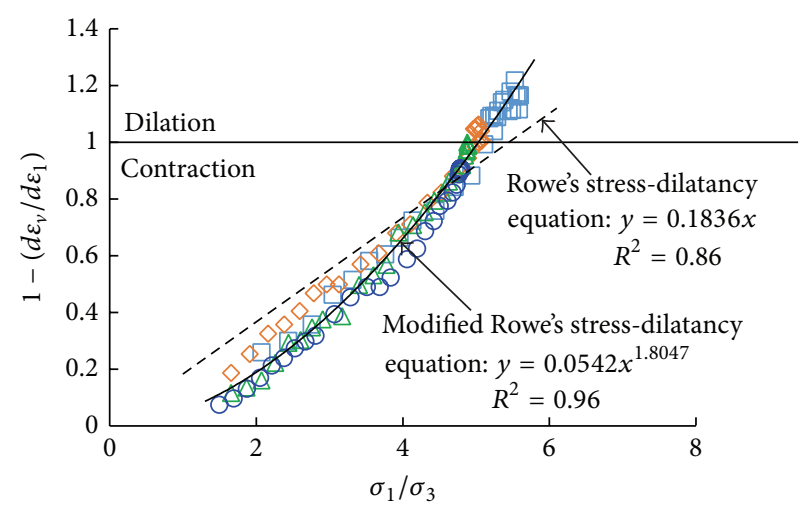

(b)

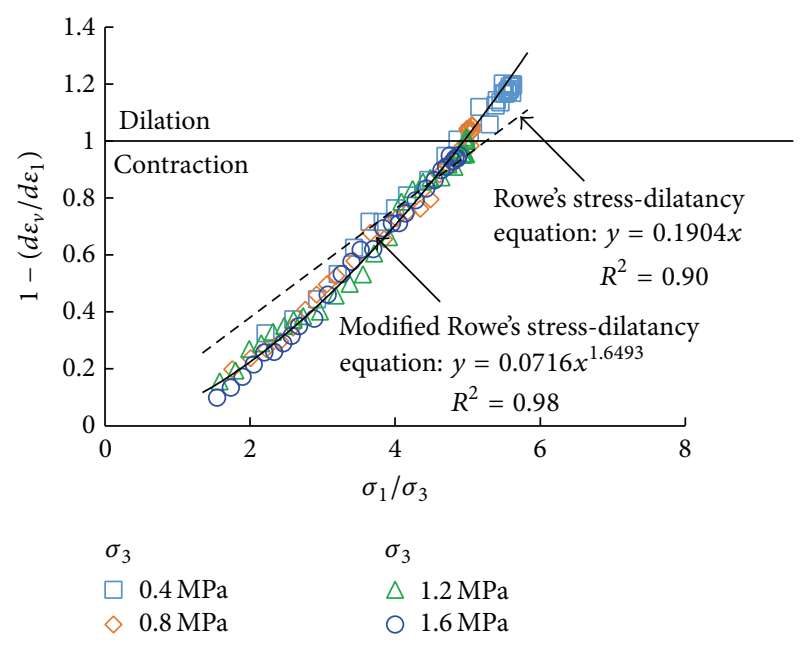

(d)

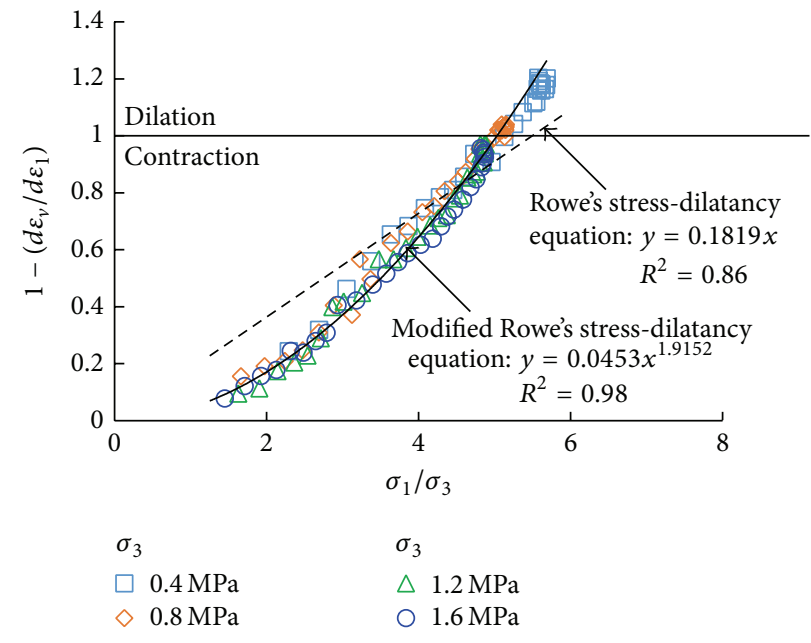

(e)

FIGURE 13: Relationship between principal stress ratio and dilatancy rate under different gradations: (a) gradation 1, rock proportion (P5), 50.89\%; (b) gradation 2, rock proportion (P5), 58.50\%; (c) gradation 3, rock proportion (P5), 66.16\%; (d) gradation 4, rock proportion (P5), $74.00 \%$; (e) gradation 5, rock proportion (P5), 82.17\%. 


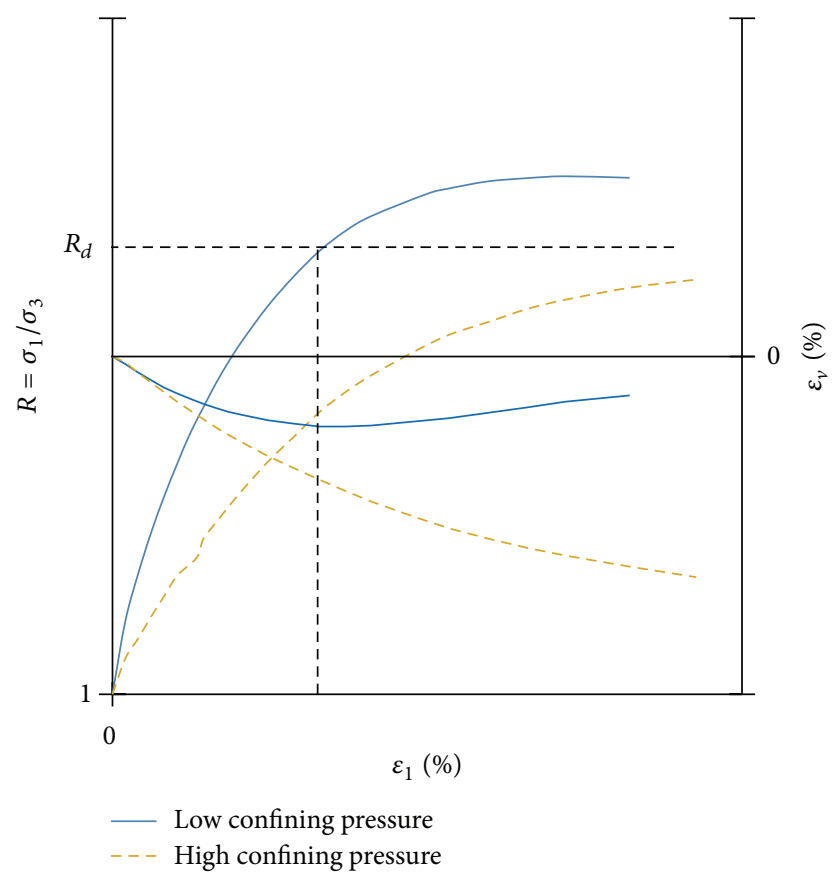

FIGURE 14: Dilatancy-contraction relationship of rock-soil aggregate expressed by the formula.

(3) Based on studying the volumetric deformation characteristics of rock-soil aggregate and the relationship between volumetric deformation and principal stress ratio, a modified Rowe's stress-dilatancy equation suitable for rock-soil aggregate is suggested.

In summary, Duncan-Chang model is to certain extent suitable for describing the deformation characteristics of rock-soil aggregate. Future study will be conducted on how to propose a practical constitutive model suitable for rocksoil aggregate by combining Duncan-Chang model and the proposed modified Rowe's stress-dilatancy equation.

\section{Conflict of Interests}

The authors declare that there is no conflict of interests regarding the publication of this paper.

\section{Acknowledgments}

This study was supported by the National Basic Research Program of China (no. 2011CB710600) and the National Natural Science Foundation of China (nos. 51379022, 51179013, and 51209021). These supports are greatly acknowledged and appreciated.

\section{References}

[1] X. U. Wenjie and H. U. Ruilin, "Conception, classification and significations of soil-rock mixture," Hydrogeology \& Engineering Geology, vol. 4, no. 6, pp. 50-56, 2009.

[2] G. Sun and B. Yao, Study on Landslide Disaster in China, Science Press, Beijing, China, 1988.
[3] E. Medley, The engineering characterization of melanges and similar block-in-matrix rocks (Bimrocks) [Ph.D. thesis], University of California, Berkeley, Calif, USA, 1994.

[4] X. Li, Q. L. Liao, and J. M. He, "In-situ tests and a stochastic structural model of rock and soil aggregate in the three gorges reservoir area, China," International Journal of Rock Mechanics and Mining Sciences, vol. 41, no. 1, pp. 2-6, 2004.

[5] Q. Liao, X. Li, Z. Hao et al., "Current status and future trends of studies on rock and soil aggregates," Journal of Engineering Geology, vol. 14, no. 06, pp. 801-807, 2006.

[6] X. You and J. Tang, "Research on horizontal push-shear insitu test of soil and rock- mixture," Chinese Journal of Rock Mechanics and Engineering, vol. 21, no. 10, pp. 1537-1540, 2002.

[7] X. Wang, Research on influence factors of mechanics characteristics and characteristics failure mechanism of soil-rock mixture [M.S. thesis], Changjiang Scientific Research Institute, 2010.

[8] W. Cheng, Study on mechanical properties test and constitutive relationship of colluvial landslide soil-rock mixture [M.S. thesis], Hohai University, 2011.

[9] W.-S. Li, X.-L. Ding, A.-Q. Wu, and S.-H. Xiong, "Shear strength degeneration of soil and rock mixture in Three Gorges Reservoir bank slopes under influence of impounding," Rock and Soil Mechanics, vol. 28, no. 7, pp. 1338-1342, 2007.

[10] Z. Zhou, H.-L. Fu, B.-C. Liu, H.-H. Tan, and W.-X. Long, "Orthogonal tests on permeability of soil-rock-mixture," Chinese Journal of Geotechnical Engineering, vol. 28, no. 9, pp. 11341138, 2006.

[11] W. Xu, R. Hu, Z. Q. Yue, R. Zhang, and G. Wang, "Research on relationship between rock block proportion and shear strength of soil-rock mixtures based on digital image analysis and large direct shear test," Chinese Journal of Rock Mechanics and Engineering, vol. 27, no. 5, pp. 996-1007, 2008.

[12] O. Zhenhua, L. Shihai, and D. Zhisheng, "On the Influence factors of mechanical properties for soil-rock mixture," Journal of Experimental Mechanics, vol. 25, no. 1, pp. 61-67, 2010.

[13] J. M. Duncan and C.-Y. Chang, "Nonlinear analysis of stress and strain in soil," ASCE Journal of the Soil Mechanics and Foundations Division, vol. 96, pp. 1629-1653, 1970.

[14] M. J. Duncan, P. Byren, K. Wong et al., "Strength, stress-strain and bulk modulous parametres for finite element analysis of stress and movements in soils masses," Report No .UCB/ GT/ 80001[R], University of California, Berkeley, Calif, USA, 1980.

[15] N. Janbu, "Soil compressibility as determined by oedometer and triaxial tests," in Proceedings of the European Conference on Soil Mechanics and Foundations Engineering, vol. 1, pp. 19-25, Wiesbaden, Germany, 1963.

[16] J. A. Charles and K. S. Watts, "The influence of confining pressure on the shear strength of compacted rockfill," Geotechnique, vol. 30, no. 4, pp. 353-367, 1980.

[17] B. Indraratna, D. Ionescu, and H. D. Christie, "Shear behavior of railway ballast based on large-scale triaxial tests," Journal of Geotechnical and Geoenvironmental Engineering, vol. 124, no. 5, pp. 439-449, 1998.

[18] P. W. Rowe, "The stress dilatancy relation for static equilibrium of an assembly of particles in contact," Proceedings of the Royal Society of London A, vol. 269, no. 1339, pp. 500-527, 1962.

[19] P. W. Rowe, "Theoretical meaning and observed values of deformation parameters for soil," in Proceedings of the StressStrain Behaviour of Soils, Roscoe Memorial Symposium, R. H. G. Parry, Ed., pp. 143-194, Cambridge University, The Whitefriars Press Ltd, London, UK, 1971. 

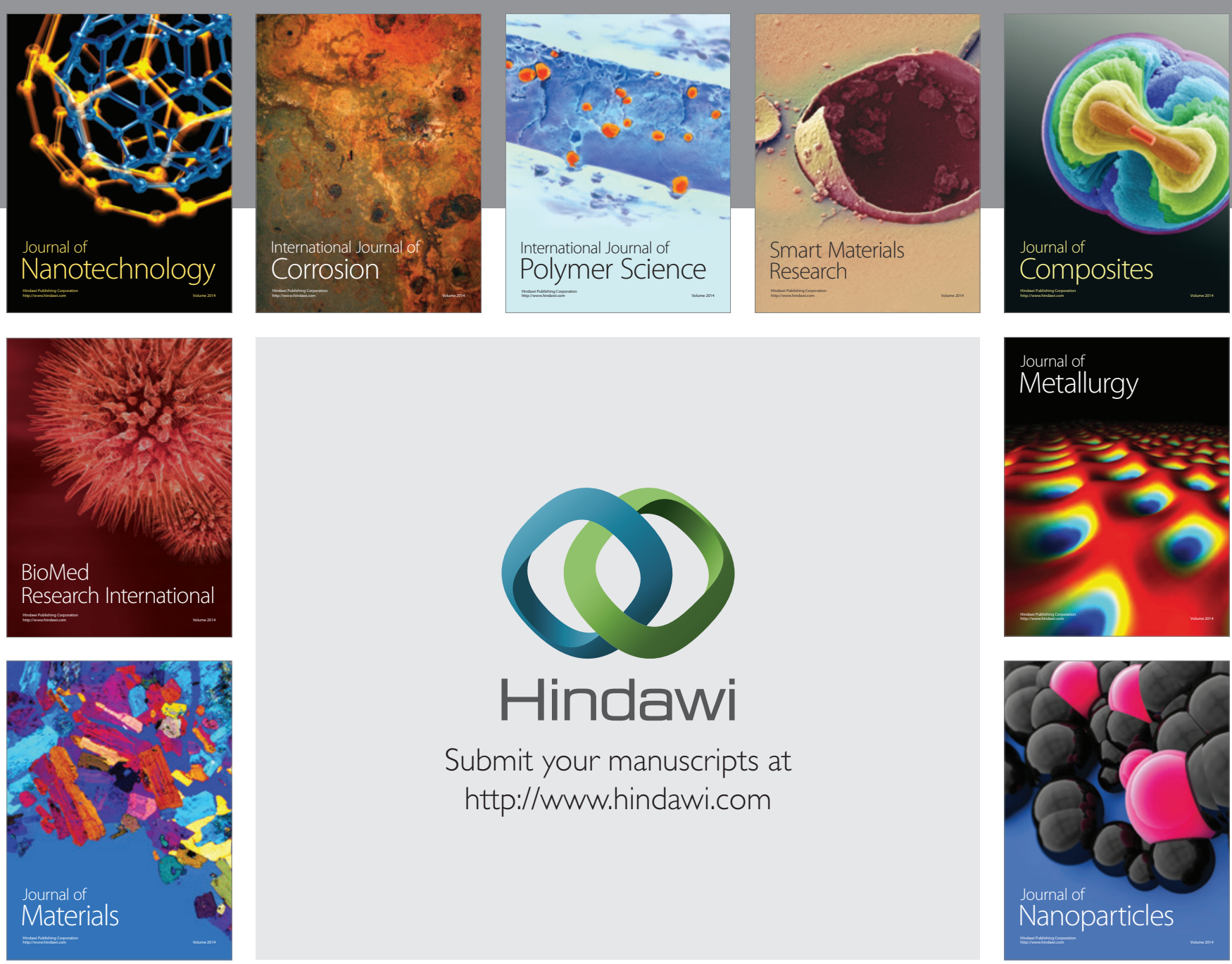

Submit your manuscripts at http://www.hindawi.com
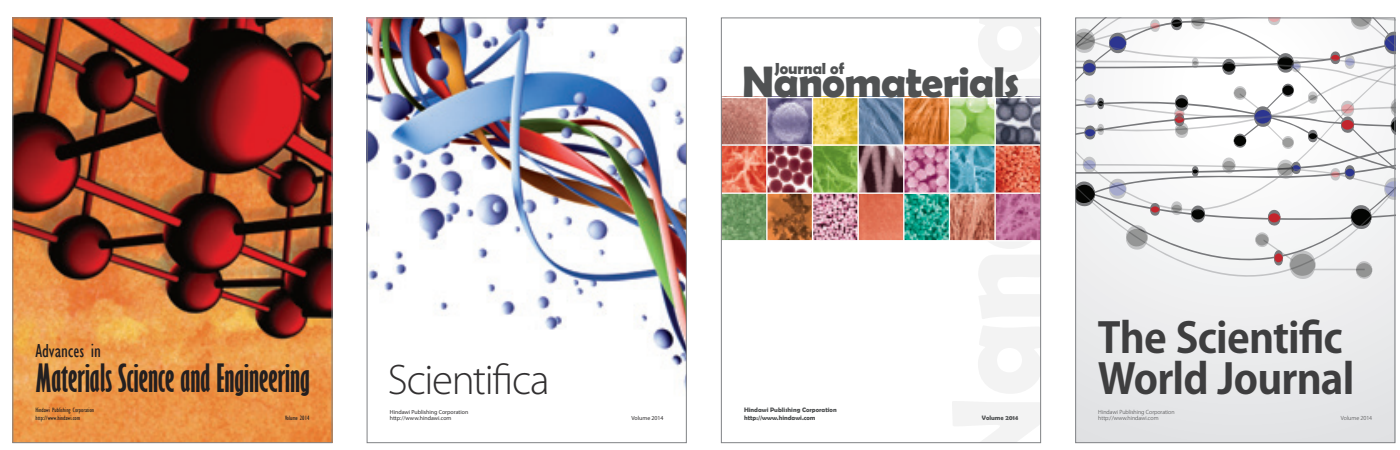

\section{The Scientific World Journal}
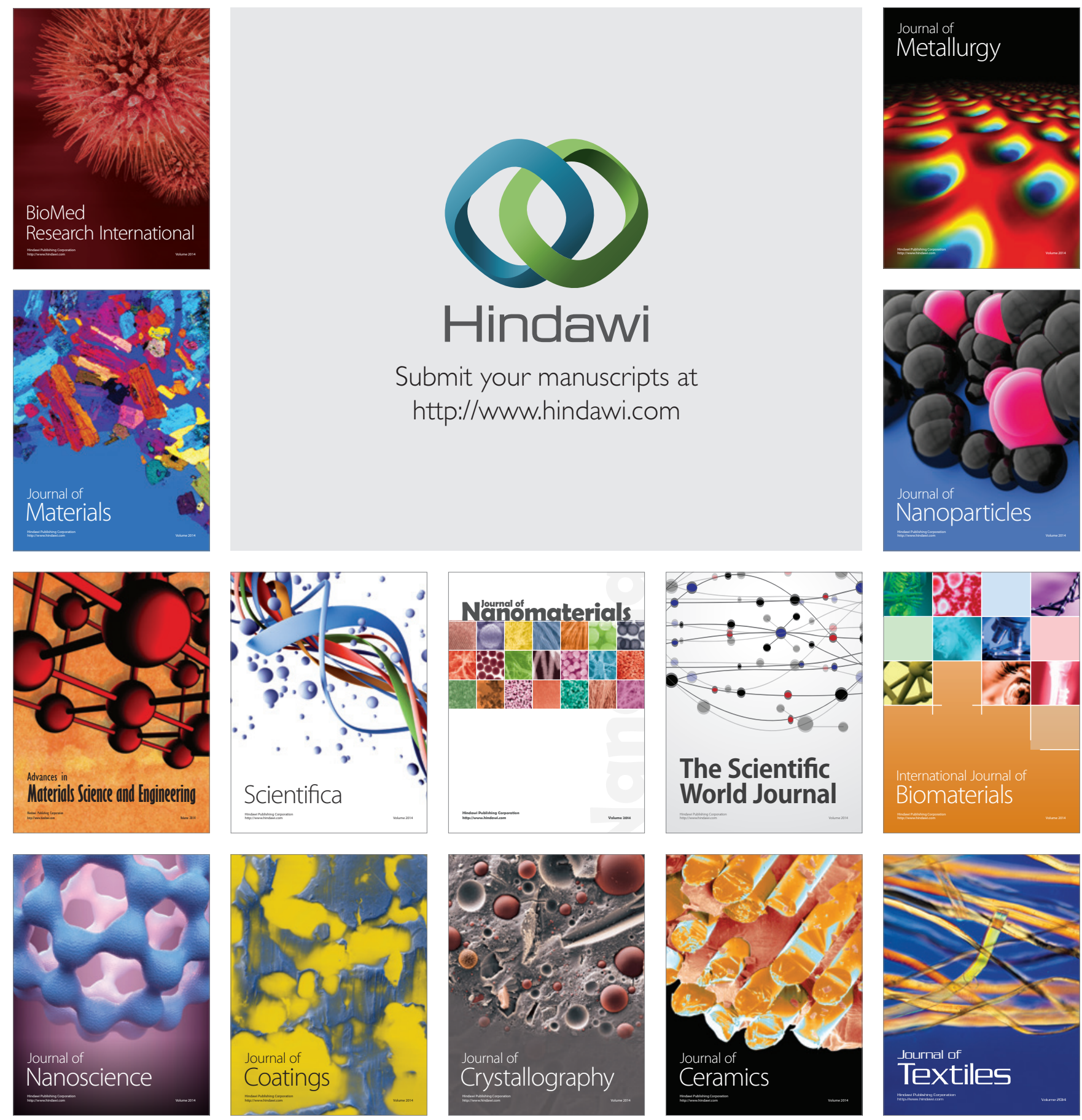